\title{
Proceeding of
}

\section{the United States}

\section{$\mathrm{N}$ a t i o n a l M u se u m}

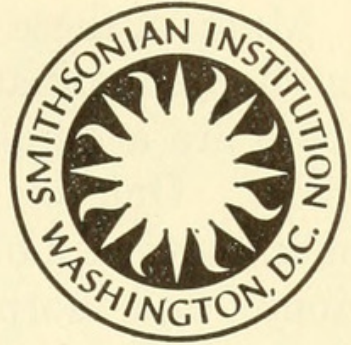

SMITHSONIAN INSTITUTION • WASHINGTON, D.C.

TAXONOMY, DISTRIBUTION, AND POLYMORPHISM IN THE LABIDOCERA JOLLAE GROUP

WITH REMARKS ON EVOLUTION WITHIN THE GROUP (COPEPODA: CALANOIDA)

\section{By Abraham Fleminger ${ }^{1}$}

\section{Introduction}

Acceptance of the idea that the prevailing mode of speciation in sexually reproducing animals begins with genetic divergence of spatially separated stocks is widespread and rightly so. With regard to the pelagic biotope of the oceans, however, this concept is based more on faith than on documentation, although several noteworthy efforts have been published (e.g., Bowman, 1955; Brinton, 1962; Ebeling, 1962; Davies, 1963).

Study of evolution in pelagic metazoans is impeded by a combination of factors, including (1) confluence of oceans and the relative obscurity of isolating barriers; (2) uncharted variability of major current systems with climatic changes over time; (3) general lack of detailed knowledge regarding the biology and range of pelagic organisms; (4) scarcity of information on the kinds and extent of morphological variation within and between populations; (5) extensive economic and logistic requirements for collecting oceanic species; (6) continuing prevalence of

${ }^{1}$ Scripps Institution of Oceanography, University of California, San Diego, Calif. 
typology in taxonomic accounts of pelagic invertebrates (cf. Simpson, 1961, pp. 45-50); and (7) paucity or absence of a fossil record for most taxa.

Many of these obstacles can be lessened materially by concentrating upon predominantly neritic taxa. Among the planktonic copepods there are a number of large, essentially neritic genera from which to select. One of these, the genus Labidocera (family Pontellidae), offers several notable advantages for examining ecological, distributional, and morphological relationships between closely related congeners. Species are relatively large in size and can be collected in abundance. Sexually modified anatomical features are speciesspecific and remarkably well developed.

Ranges, which are limited to warm-temperate to tropical latitudes, are sharply defined and tend to coincide with major zoogeographic as well as inshore-offshore boundaries (Fleminger 1957, 1959; Heinrich, 1960; Voronina, 1962, 1964; Sherman, 1963, 1964). Range limits conforming to oceanic barriers on the one hand and latitudinal zonation on the other are relatively simple to determine and monitor for an extended period of time. This lattermost feature confers added advantages to the study of neritic Labidocera in the Western Hemisphere, where several distinctive species groups are found. These species groups are adapted to coastal waters. Within a group, the distribution and taxonomic relationships of its species constitute a series of succeeding ranges like successive links in a chain. Taxonomic, morphological, and distributional relationships within and between species groups of Labidocera found in the Western Hemisphere are under study, one objective being to disclose patterns of evolutionary consequence operating interspecifically on planktonic copepods.

Seven species of Labidocera are known to occur on the Pacific Coast of the Americas (Giesbrecht, 1892; Esterly, 1905, 1906; Johnson, 1935; Wilson, 1942, 1950; Sherman, 1963; Fleminger, 1964a). ${ }^{2}$ Of these, $L$. acutifrons and $L$. detruncata are typically oceanic, whereas L. acuta is more closely associated with continental and insular land masses. Three, L. trispinosa, L. johnsoni, and L. jollae, have been found chiefly in inshore waters off California and northern Mexico while the remaining species, L. lubbockii, is known only from the type locality, Golfo de Guayaquil, Ecuador. In the present study two additional species have been found.

The two new species are closely related to $L$. jollae, and the three together comprise the subject of this paper. One of the new species is especially noteworthy in that it is conspicuously dimorphic in the

\footnotetext{
${ }^{2}$ Some of the records of Labidocera published by Wilson (1950) have been omitted for reasons discussed elsewhere (Fleminger, 1965).
} 
male sex. Following description of the three species, ranges and interspecific relationships are discussed with special regard to their bearing on evolution within the group.

The genus Labidocera was established by Lubbock (1853) for a new species, $L$. darwinii Lubbock, collected off Argentina at latitude $38^{\circ} 5^{\prime}$ S. More than 40 species have subsequently been described. Although substantial revision of this complex is necessary, it must be delayed due to the lack of appropriate collections for study. In this report the genus Labidocera is used in the sense of Giesbrecht (1892) and refers to those pontellids with (1) one pair of dorsal subcuticular lenses in forehead; (2) rostrum deeply bifurcated and lacking a lense; (3) medioventral eye protuberant and extending anteroventrad between rostral prongs; (4) first pair of swimming legs with two-segmented endopod; (5) male right antennule with at least four separate segments distal to hinge between segment 18 and fusion segment 19-21; (6) maxillule with basipod about twice the length of endite 2, maxilliped with six distinct segments.

Roughly 20 percent of the species of Labidocera, including the jollae group, bear lateral head-hooks, which are obscure structures best seen in dorsal view. All are coastal in habitat. Most are restricted to the Indian and western Pacific Oceans although one is found in the northeast Atlantic and the jollae group occurs along the west coast of North America. Their phylogenetic relationships are not yet established; however, zoogeographically reasonable groups can be sorted out using segmentation of the antennule, sexually modified appendages, and female urosome segmentation. On this basis the jollae group can be regarded as being monophyletic and widely separated from the other head-hooked species. Extrapolating from present day ranges, no other head-hooked Labidocera has occupied any portion of the Western Hemisphere-at least since late Pleistocene.

This research was partially supported by National Science Foundation Grants G 19417 and GB 2861. A large number of plankton samples used in this study were obtained through the generous cooperation of colleagues with Scripps Institution of Oceanography, the Bureau of Commercial Fisheries, La Jolla Laboratory, and the Inter-American Tropical Tuna Commission. Especially notable contributions of coastal plankton were made by T. Matsui, S. Kato, R. H. Rosenblatt, F. H. Berry, B. Zahuranec, W. Klawe, and M. Gilmartin. I have been greatly helped with preparation of the manuscript by the thoughtful council of C. R. Stasek, who read an early draft, and by T. E. Bowman and several members of the curatorial staff of the U.S. National Museum, who read the final draft. 


\section{Methods}

Measurements.-In general, the procedures of Fleminger (1957) were followed. All measurements were taken with an ocular micrometer from specimens mounted in glycerine; prosome and urosome were measured at $62.5 \times$ magnification using a stereoscopic microscope; individual segments were measured at $80 \times$ magnification using a compound microscope. No allowance for telescoping or expansion at joints has been made, but damaged specimens have been omitted. Total length (TL) was routinely measured and the prosome-urosome length ratio (PUR) was calculated. Details of special measurments are presented in the text. All figures were drawn with the aid of a camera lucida.

Collections.-Plankton samples used in this study were obtained by three kinds of tow. Most collections were CalCOFI (California Cooperative Oceanic Fisheries Investigations standard plankton tow) oblique tows (140 meters to the surface), taken with a one-meter net $(1 \mathrm{~m} / \mathrm{O}$; cf. Berner and Reid, 1961, or Fleminger, 1964b, for more extensive description). Some collections were obtained from a series of vertically stratified horizontal net tows taken at various depths by one-meter, Leavitt-type, opening-closing nets $(1 \mathrm{~m} / \mathrm{H}$; cf. Ahlstrom, 1959, for description). Much of the coastal material from the Gulf of California was collected by standard conical nets (no. 333 Nytex mesh) roughly $1 / 2 \mathrm{~m}$ in diameter $(1 / 2 \mathrm{~m})$. A $1 / 2 \mathrm{~m}$ conical net constructed of monel mesh $\left(\frac{1}{2} \mathrm{~m} / \mathrm{HS}\right)$ and patterned after the cone of the Gulf-III Sampler (Gehringer, 1952) was used at some stations off southern Baja California. The $1 / 2 \mathrm{~m}$ and $1 / 2 \mathrm{~m} / \mathrm{HS}$ nets were towed within five miles of the intertidal between the surface and five meters for periods of 5 to 15 minutes depending on locality. Some collections were taken by vertical tows and are referred to in the tables by "V" placed after net type. Station locations are shown in figure 2.

\section{Morphological Terminology}

The abbreviations of Giesbrecht and Schmeil (1898), later repeated by Rose (1933), afford a practical means for dealing with calanoid morphology in the light of the unresolved problem of homologizing it with malacostracan morphology (Illg, 1958). With widespread usage these abbreviations would simplify descriptive sections, but, unfortunately, they have not been utilized as frequently as their merits warrant. To reduce copepod morphological ambiguities, Gooding $(1957,1960)$ has tabulated and carefully defined terms and abbreviations frequently misused. His definitions are followed in the present paper.

It seems useful to review briefly the terminology used in this and future papers of this series on Labidocera. The calanoid body is 
divisible into three primary tagmata, the cephalosome, the metasome, and the urosome. The cephalosome consists of the cephalic somites bearing the antennules (A1), the antennae (A2), the mandibles (Mnd), the maxillules $\left(\mathrm{Mx}_{1}\right)$, and the maxillae $\left(\mathrm{Mx}_{2}\right)$, and the first true thoracic somite bearing the maxillipeds (Mxp). The metasome contains the five thoracic somites (TI-V) that bear the swimming legs (P1-5), the last pair (P5) at least being sexually modified. The cephalosome and metasome jointly make up the prosome, i.e., all body segments anterior to the major articulation between TV and the genital segment. The urosome begins with the genital segment and contains four or less abdominal segments, the last one being the anal (perianal) segment bearing the caudal rami.

The swimming legs consist of two basal segments, B1 proximal and B2 distal, together referred to as the protopodite, and two distal rami, the lateral exopod $(\mathrm{Re})$ and the medial endopod ( $\mathrm{Ri})$. The segments of the rami are numbered in sequence from proximal to distal joint; e.g., second segment of the exopod of the fourth pair of legs would be referred to as $\mathrm{Re} 2$ of $\mathrm{P} 4$. The larger articulating elements on the segments of appendages are lateral (Se), medial (Si), or terminal (St), and are numbered proximal to distal, a new sequence beginning with each segment. Spinules and hairs (cilia) also articulate or arise from sockets. Nonarticulating structures, or those imperfectly separated from the parent element by a weak line of constriction but lacking an apparent line of flexure, are treated as a general class of processes with appropriate descriptive adjectives to denote form.

The genital pore or antrum (Fahrenbach, 1962) is a cuticular-lined depression on the sternum of the genital segment into which the oviducts (gonopores) open. The gonopores are incompletely shielded by a genital plate articulating along its anterior margin and possibly free along its posterior margin.

Dentition of the mandibular gnathobase appears to be a useful phylogenetic tool, at least for the higher taxa of calanoid copepods. Relationships have been noted between shape and arrangement of the teeth and the kind and condition of the food observed in gut analyses of a number of different species (Fleminger, 1956; Beklemishev, 1959; Anaraku and Omori, 1963).

Giesbrecht (1892, pl. 8, figs. 4, 8, 11) did not propose a formal nomenclature but sometimes numbered the teeth in a ventral to dorsal sequence. Beklemishev (1959) has employed a similar system of letters and numbers. Interfamily homologies in dentition are not established, but an empirical system for Pontellidae has been derived from a survey of pontellid genera (Fleminger, unpubl.) and is used in the descriptions that follow. For the subfamily Eupontellinae, three groups of teeth can be distinguished. Group 1 consists of the two 
ventralmost teeth, the apical and subapical, which are the largest, usually unicuspidate, and widely separated by a deeply cut, rounded notch. Group 2 includes the three medial teeth, which are usually bicuspidate and separated by narrower, shallower notches, and a minute intercalary tooth, which may occur between medials 1 and 2 and medials 2 and 3 . Group 3, the dorsalmost teeth, are referred to as basals. They extend dorsomediad into the mouth field instead of medial like the others. Basal teeth are usually acuminate, unicuspidate, and closely spaced; they vary in number from one to four and often present useful specific characters. A seta is also present in the subfamily Eupontellinae and is located dorsal to the basals. Several rows of scalelike accessory spines and patches of spinules occur adjacent to the dentition, but they have not been used in this system.

Holotypes, allotypes, and reference specimens have been deposited in the U.S. National Museum (USNM). Reference specimens have also been deposited in the Marine Invertebrate Collections of Scripps Institution of Oceanography (SMIC).

\section{Labidocera jollae Esterly}

Figures 1,10

Labidocera jollae Esterly, 1906, p. 74, pls. 9 (figs. 22, 23), 12 (figs. 50-53), 14 (figs. 89, 91).-Johnson, 1935, p. 411, pls. 3 (figs. 1-3), 4 (figs. 1, 3, 11, 13, 1719, 20-21), 5 (figs. 3-8) [moult stages described].

Localities, materials.-See table 1.

LENGTH AND BODY PROPORTIONs.-Adult and stage V copepodite measurements, excluding caudal setae, of specimens selected at random are as follows:

\begin{tabular}{|c|c|c|c|c|c|c|}
\hline & \multirow[b]{2}{*}{ no. } & \multicolumn{3}{|c|}{ Total Length (mm) } & \multicolumn{2}{|c|}{$\begin{array}{l}\text { Prosome-Urosome Length } \\
\text { Ratio }\end{array}$} \\
\hline & & mean & range & st. dev. & median & range \\
\hline adult $q$ & 63 & 2.69 & $2.07-3.07$ & 0.152 & $4.1: 1$ & $3.6-4.9: 1$ \\
\hline adult $\sigma^{x}$ & 60 & 2.26 & $1.93-2.61$ & 0.121 & $2.9: 1$ & $2.5-3.3: 1$ \\
\hline stage V cop. ㅇ & 14 & 2.02 & $1.81-2.23$ & & $4.2: 1$ & $4.0-4.6: 1$ \\
\hline stage $\mathrm{V}$ cop. $\sigma^{7}$ & 15 & 1.80 & $1.72-1.92$ & & $3.3: 1$ & $3.0-3.5: 1$ \\
\hline
\end{tabular}

Description.-Adult female: Overall appearance stocky, urosome short relative to prosome, latter roughly four times length of former, forehead armed with pair of lateral hooks. A1 short relative to prosome, when extended posteriad reaching articulation between TIII and TIV. Urosome two segmented; genital segment large, asymmetrical, anal segment exceedingly short. In dorsal view (fig. 1d) genital segment with two anterolateral swellings: one on right side larger, knoblike, one on left side a low boss; genital pore lateral, opening on right side. Caudal rami asymmetrical, right ramus 
larger, inflated, left ramus somewhat reduced, setation concentrated at distal end; setae of both rami relatively short, less than length of urosome, proximal portions not expanded.

TIV and TV separated by a distinct suture. In dorsal view TV asymmetrical, left posterior corner larger than right, both corners strongly flared, maximum width between apex of left and right TV corners about 1.2 times larger than maximum width of preceding segment (fig. $1 d$ ).

P5 with exopod bearing two lateral denticles and one short apical spine; endopod small, imperfectly separated from B2 by weak constriction (fig. $1 h$ ).

Spermatophore, in general, resembles that found in Labidocera mirabilis (Fleminger, 1957). Coupler ("Koppler," Heberer, 1932= accessory ornamentation, Fleminger, 1957) relatively large, cemented to ventral side of urosome; in ventral view (fig. $1 f$ ) appearing as large, somewhat rectangular plate obscuring the urosome. Left and right sides of coupler extending laterodorsad in ovate lobes that flank right and left sides of urosome (fig. 1e). Left lobe longer and higher than right lobe, both extending dorsad well above uppermost limit of genital segment (fig. $1 \mathrm{~g}$ ) ; occasionally, lobe tending to flare laterally, decreasing height relative to genital segment. Spermatophore sac short, about as long as, and located ventral to, right caudal ramus (fig. 1g).

Adult male: Head-hooks present. TIV and TV separate. TV corners symmetrical, not expanded, each side ending in a minute denticle; caudal rami comparatively long, equal to combined lengths of preceding four segments (fig. 1b); rostrum asymmetrical, right prong reduced, left prong as in female (figs. 1l, 10).

Hinged right A1 (fig. 1a), in dorsal view, with segment 17 expanded anteriad in an arched ridge lightly sculptured with irregular ribbing; ridge lacking denticles. Segment 17 wider (anterior-posterior limits) than long (proximal-distal limits), mean of ratio $\mathrm{W} / \mathrm{L}=1.190$, range 1.0-1.5 (22 specimens selected at random). Segment 18 with two parallel rows of slender, closely spaced denticles; fusion segment 19-21 with single row of blunter, shorter denticles, row extending threequarters length of segment; fusion segment 19-21 roughly twice length of segment 18.

P1 with unusual asymmetry in external spines on exopod of right leg; Se1 of Re1, Re2, and Re3 elongate, distal portion swollen; same spines on exopod of left leg normal (fig. $1 \mathrm{~m}$ ).

Right P5 (fig. 1c) with large chela; both segments comprising chela elongate, slender, crescent shaped and lacking pronounced lamelliform ridges; straight line distance between origin and apex of distal segment about equal to length of right protopodite; proximal and distal 


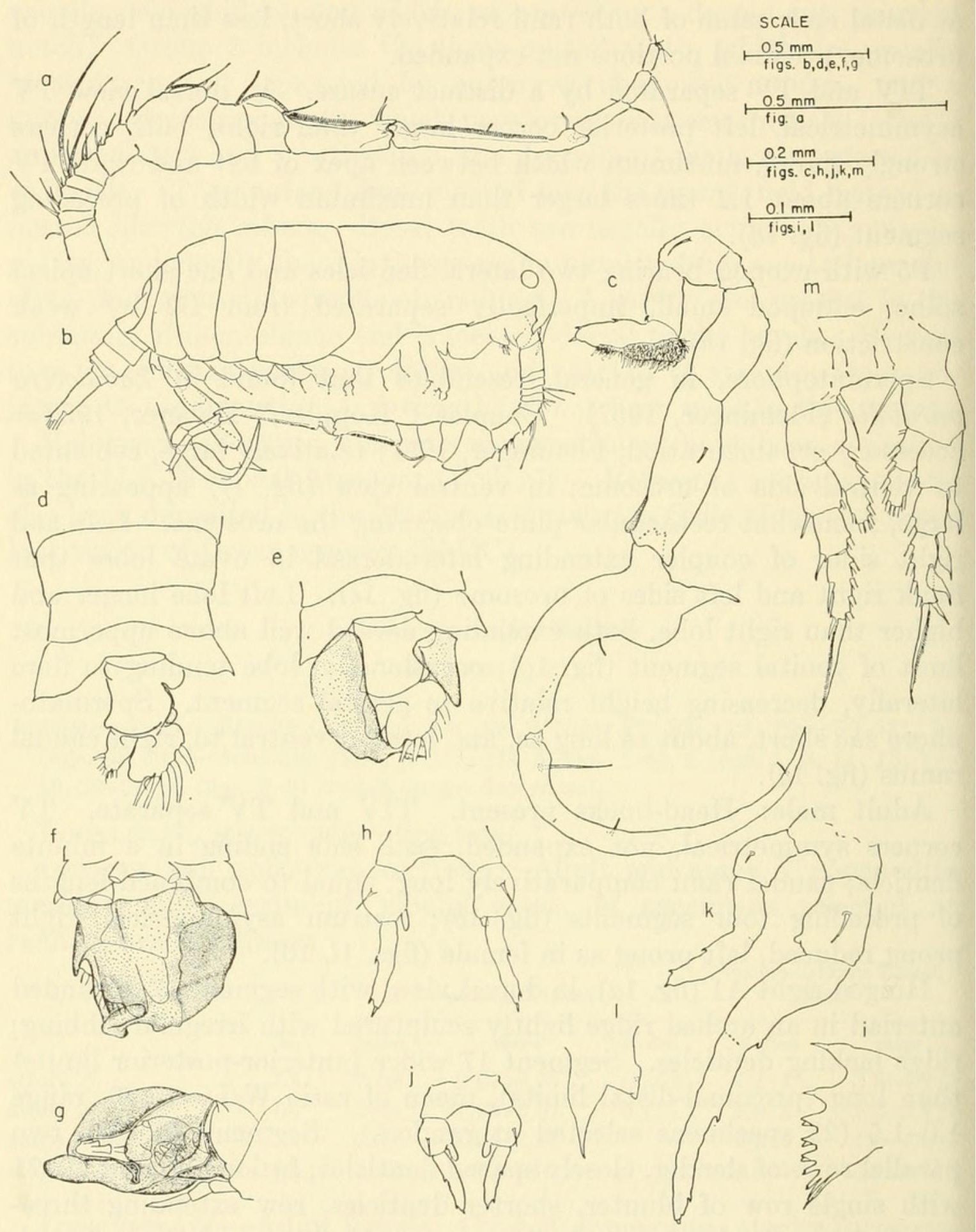

Figure 1.-Labidocera jollae Esterly, adult male: $a$, right $\mathrm{A} 1$, setation incomplete; $b$, right lateral view, appendages incomplete; $c, \mathrm{P} 5$, posterior view; $l$, rostrum, posterior view; $m, \mathrm{P} 1$, posterior view. Adult female: $d$, posterior half of body, dorsal view; $e$, posterior half of body with spermatophore, dorsal view; $f$, posterior half of body with spermatophore, ventral view (terminal segments of $\mathrm{P} 5$ omitted); $g$, posterior half of body with spermatophore, right lateral view; $h, \mathrm{P} 5$, posterior view; $i$, right mandibular gnathobase, anterior view. Penultimate stage, $\mathrm{P} 5$, posterior view: $j$, female; $k$, male. 
segments articulate at medialmost extension of chela; when chela closed, apex of distal segment crosses proximal segment near articulation with B2 between prominant ovate swelling and lateral attenuated prong. Left P5 (fig. 1c) relatively short, pediform; apical segment hirsute on medial face, bearing two short distal spines, one lateral spine at midlength.

No appreciable variation was observed in the proportions of the spermatophore, the flaring of the TV corners in the female, the male $\mathrm{P} 5$ and the male right $\mathrm{A} 1$.

Additional Description.- Right A1 of adult male with partial to complete tagmosis of the following segments: $8-9,10-12,13-14$, 19-21, 24-25 (based on numbering system of Giesbrecht, 1892). A1 of adult female and left $\mathrm{A} 1$ of adult male with 23 perfectly separated segments; segments 8-9 imperfectly fused, segments $24-25$ perfectly fused.

Gnathobase of Mnd (fig. 1i) with apical and subapical teeth acuminate; median teeth 1-3 bicuspidate, each cusp pointed. Three large basal teeth present, basals 1 and 2 usually bifid, basal 3 simple, acuminate.

Johnson (1935, pl. 4, fig. 11) noted only seven teeth on the mandibular gnathobase of jollae; his illustration lacks one of the three basals found in the present study. He has suggested (personal communication) that the third basal tooth may have been overlooked since he used relatively low magnifications to examine the mandible.

Adult female with symmetrical rostrum (fig. 10b), prongs robust, proximal portion expanded, in frontal view prongs separated by angular notch. Diameter of subcuticular dorsal eye lenses similar in both sexes, not exhibiting the strong sexual dimorphism common to most other species of the genus.

Penultimate stage female: Urosome with three segments. Corners of TV not expanded, similar to penultimate stage male. P5 in general resembles that in adult but with relatively smaller processes (fig. $1 j$ ). A1 extends to posterior end of TII. Genital segment occasionally with precocious, more or less incompletely developed genital pore.

Penultimate stage male: Urosome with four segments. Right A1 with middle segments moderately expanded proximal to site of subsequent hinge. Right P5 (fig. $1 k$ ) with B2 bearing mediodistal, knoblike protuberance regarded as the endopod precursor. Left B2 with smaller, less distinct protuberance. Right and left B1 fused, ventral margin with asymmetrical notch closer to left leg. Right exopod unisegmented with constriction just distal to proximalmost spinous process. Left exopod unisegmented, shorter, width in posterior view essentially constant from origin to first lateral denticle. Johnson (1935, pl. 4, fig. 20) shows endopods of penultimate stage male P5 separated from 
B2 by suture or marked constriction. This condition was not found in the material examined during the present study.

Coloration.-Two sets of prominent carmine-colored bodies in the prosome and the red pigment cup of the ventral eye generally persist for some time in material kept in 5 percent solution of formaldehyde in sea water. The carmine-colored bodies occur in pairs lateral to the midline, the anterior pair being straplike and lying between TI and TII immediately dorsal to the sternum. The posterior pair vary in shape and in the number of lobes or particles. One clump is found on each side of the gut usually at midlength of TIII. In the adult male the left member of the TIII pair is typically absent. The cuticle is generally colorless except for a faint blue tint in the swimming legs.

Alive, adults are blue green, the intensity of the hue over the entire body varying from light to heavy. The blue-green color is located under the cuticle. It is not restricted to the epidermis but appears diffused throughout the outermost muscle layers. Lateral pairs of reddish-orange chromatophores to the right and left of the midline were observed in the prosome. The chromatophores are uniformly distributed, there being in general two pairs per pair of prosomal appendages. One pair is ventrolateral and can be observed in lateral view where it is seen near the ventral margin of the pleuron. The other pair seen in ventral view is associated with the appendage's B1.

Movement of pigment in these chromatophores was observed to be slow. About one minute was required for a chromatophore to change from the reticulate stage of total pigment dispersion to the punctate state of extreme concentration. I have observed somewhat similar chromatophores in Pontellopsis occidentalis and Labidocera acuta. There is reason to believe that pigmentation will play a useful role in studies of habitat and mate selection in Pontellidae and such data should be systematically gathered and made available.

Types.-Esterly (1906, p. 75) refers to two specimens of jollae, a female "taken on the surface three and one-half miles from La Jolla, June 26, 1905," and a male collected "in the cove of La Jolla, Janaury 2 , 1906," as the types that he deposited in the collections of the University of California.

None of the specimens of jollae that I found in the Esterly Collection held in the Scripps Marine Invertebrate Collections were designated by label as a type specimen. Collecting data on the label of one male, however, matches the collecting details presented in the original description. Some of the appendages are missing (right $\mathrm{A} 1, \mathrm{P} 1-5)$. The same kind and number of appendages are mounted 
on a slide in the Esterly Collection that bears the name of the species, but lacks other distinguishing remarks. The close similarity of Esterly's figures of the male P5 with the position of the P5 on the slide suggests that the slide and the tubed specimen comprise the male component of Esterly's original specimens.

One of the two females found in the Esterly Collection may be the other syntype. The two females were together in the same vial, labeled "Labidocera jollae Esterly, o ad., 1158." Tow number 1158 refers to a surface tow taken on June 29, 1906 between 0505-0520 hrs. at latitude $32^{\circ} 52.3^{\prime} \mathrm{N}$, longitude $117^{\circ} 16.4^{\prime} \mathrm{W}$ (off San Diego). It is possible and even likely that only one of the two females was taken at station 1158, and that the other specimen is the missing syntype from La Jolla cove (3.5 miles off La Jolla, June 26, 1905); but there is no way of distinguishing one from the other. The male specimen is, therefore, designated the lectotype.

The lectotype and one of the females are deposited in the USNM, 110762. The other female and a male specimen collected by Esterly at a later date (tow 2104, Mar. 17, 1910, 1934 hrs., lat. $32^{\circ} 50.6^{\prime} \mathrm{N}$, long. $117^{\circ} 29.2^{\prime} \mathrm{W}$ ) are deposited in the SMIC, XVIII-3012 and XVIII-3011, respectively.

Distribution.-Localities and collecting data are presented in table 1. These records comprise all of the captures observed in examination of several hundred plankton samples taken in the California Current, the eastern-equatorial Pacific Ocean, and the Gulf of California (fig. 2). L. jollae occurred chiefly in inshore samples characterized by a coastal-neritic assemblage of zooplankton.

The species has not been reported from any region outside of the range established by the records in table 1. It was not found in earlier coastal water studies undertaken north of Point Conception (Esterly, 1924; Campbell, 1929a, 1929b, 1930; Johnson, 1932; Davis, 1949; Le Brasseur, 1955, 1956a, 1956b; Legare, 1957; Cameron, 1957). It is not in the Aleutians list (Anraku, 1954) nor has it been reported from the northwest Pacific (Brodsky, 1950). Turning to the eastern equatorial Pacific it is absent from both Giesbrecht's (1895) and Wilson's $(1942,1950)$ lists.

The present range of $L$. jollae, then, apparently does not extend north of Cape Mendocino, California, nor south of Cabo San Lucas, Baja California. Within these limits it is confined to near-shore waters. Most of the geographical records fall between Point Conception and Sebastian Viscaino Bay (table 1, fig. 11). North of Point Conception, and extending west along the Aleutians to Asia, jollae is replaced by Epilabidocera longipedata (Sato) $[=E$. amphitrites 
(McMurrich)]. South of Magdalena Bay, Baja California, jollae is replaced by Labidocera diandra, new species, which is described below.

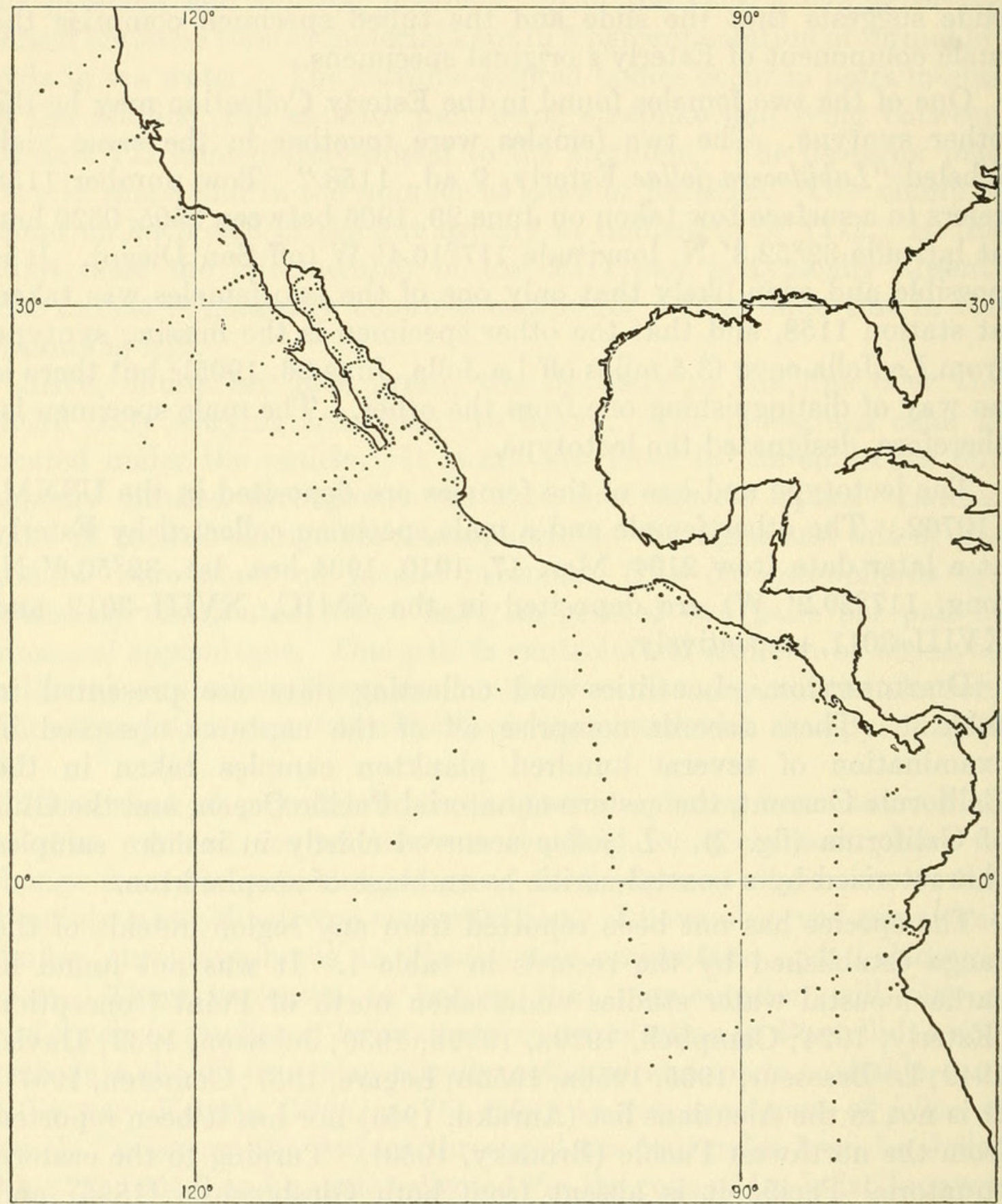

Figure 2.-Location of plankton samples examined for Labidocera. CalCOFI stations (parallel lines perpendicular to the coasts of California and Baja California) have been occupied regularly since 1950; from them one or more samples from each seasonal quarter of one year were examined.

\section{Labidocera kolpos, new species}

Figures 3-5, 10

Localities, materials.-See table 2.

LENGTH AND BODY PROPORTIONS.-Adult and stage V copepodite 
measurements, excluding caudal setae, of specimens selected at random are as follows:

\begin{tabular}{|c|c|c|c|c|c|c|}
\hline \multirow[b]{3}{*}{ adult $q$} & \multirow{3}{*}{$\begin{array}{l}\text { no. } \\
54\end{array}$} & \multicolumn{3}{|c|}{ Total Length (mm) } & \multicolumn{2}{|c|}{$\begin{array}{c}\text { Prosome-Urosome Length } \\
\text { Ratio }\end{array}$} \\
\hline & & mean & range & st. dev. & median & range \\
\hline & & 2.66 & $2.18-2.97$ & 0.152 & $4.3: 1$ & $3.6-5.0: 1$ \\
\hline adult $\sigma^{7}$ & 61 & 2.10 & $1.91-2.30$ & 0.089 & $3.0: 1$ & $2.8-3.6: 1$ \\
\hline st. V cop. $\nmid$ & 6 & 1.99 & $1.90-2.07$ & & $4.2: 1$ & $4.0-4.6: 1$ \\
\hline st. V cop. $\sigma^{7}$ & 7 & 1.75 & $1.63-1.88$ & & $3.4: 1$ & $3.2-3.6: 1$ \\
\hline
\end{tabular}

Diagnosis.-An allopatric twin species of L. jollae, morphologically similar in general features, but showing several constant differences in sexual structure. The name kolpos [Greek] refers to the geographical region (Gulf of California) inhabited by the new species.

Adult female: Greatest width of TV, in dorsal view, approximately equal to greatest width of preceding segment (fig. $3 f$ ). TV corners weakly flared, maximum width between corners about 15 percent less than that in jollae of equal prosome length (fig. $4 d$ ). P5 with vestigial endopod perfectly fused to B2 (figs. $3 j, l$ ). Mandibular gnathobase with cusps of median teeth rounded at apex (fig. $3 k$ ). Spermatophore, in lateral view, with left and right lobes low, closely appressed to dorsolateral portions of genital segment, lobes not extending beyond dorsal limit of genital segment (figs. $3 g-i$ ); in jollae lobes larger and not flattened but extending conspicuously above genital segment. Rostrum as in jollae (fig. 10c).

Adult male: Chela of right P5 similar in form but smaller in proportion to protopodite and left ramus than in jollae; shortest length of distal segment, measured along imaginary straight line between proximal and distal ends, excluding spine, equal to lengths of B2 plus half of B1 (fig. $3 c$ ); in jollae this width equal to total length of both segments of protopodite. Inner circumference of chela about half the length of that in jollae, although protopodite only slightly smaller (fig. 5). In closed chela, apex of distal segment crosses proximal segment near articulation with B2 between weak swelling and stout lateral prong. Rostrum as in jollae (figs. $3 n, 10 c$ ).

Right A1 (fig. $3 a$ ) in dorsal view with segment 17 almost twice as long as wide, mean of ratio $\mathrm{W} / \mathrm{L}=0.57$, range $.50-.64$ (22 specimens), anterior edge produced in shallow ridge; ridge more weakly sculptured than in jollae; segment 18 with two rows of teeth as in jollae; fusion segment 19-21 with row of small denticles extending about half length of total segment; segment 19-21 about one and one-half times length of segment 18 . Compared with jollae, length of segment 17 is slightly greater, length of segment 18 is slightly less, length of segment $19-21$ is considerably less (figs. $4 a-c$ ).

Additional description.- $L$. jollae and kolpos share the following characters: Female A1 and male left A1 with 23 perfectly 


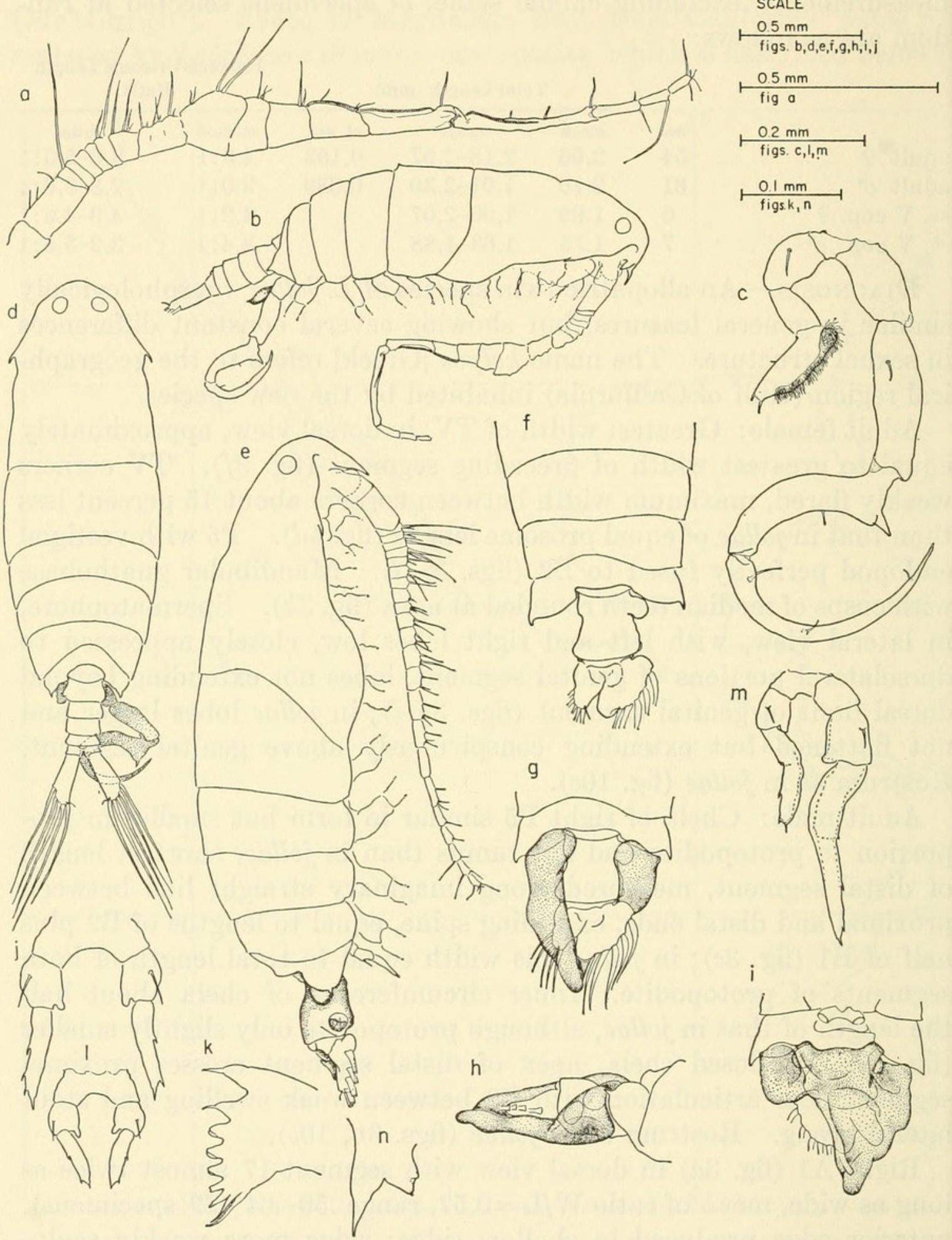

Figure 3.-Labidocera kolpos, new species, adult male: $a$, right A1, setation and dentition approximated; $b$, right lateral view, appendages incomplete; $c, \mathrm{P} 5$, posterior view; $d$, dorsal view; $n$, rostrum, posterior view. Adult female: $e$, right lateral view, appendages incomplete; $f$, posterior half of body, dorsal view; $g$, posterior half of body, dorsal view, with spermatophore; $h$, posterior half of body, right lateral view, with spermatophore; $i$, posterior half of body, ventral view, with spermatophore; $j, \mathrm{P} 5$, posterior view; $k$, right mandible, gnathobase, anterior view. Penultimate stage, P5, posterior view: $l$, female; $m$, male. 
separated segments, segments 8-9 imperfectly fused, segments 24-25 perfectly fused; right A1 of adult male with partial to complete fusion of the following segments: 8-9, 10-12, 13-14, 19-21, 24-25.

Exopod of P5 in adult female occasionally with extra lateral spinous prong as in figure $3 j$.

Right P1 of adult male with Se2 of Re3 not swollen, Se1 of Re1-3 swollen as in jollae.

Penultimate stage male with right leg of P5 (fig. $3 m$ ) bearing 2-3 minute, lateral denticles and one terminal prong. P5 of penultimate stage female resembles that of adult except for proportional relationships of segments (fig. $3 l$ ).
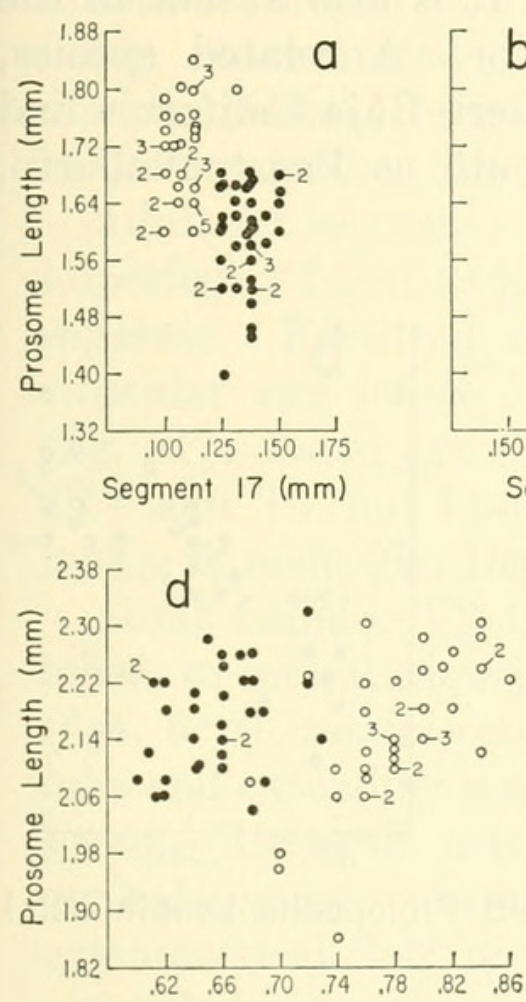

Adult $q$ TZ Width (mm)

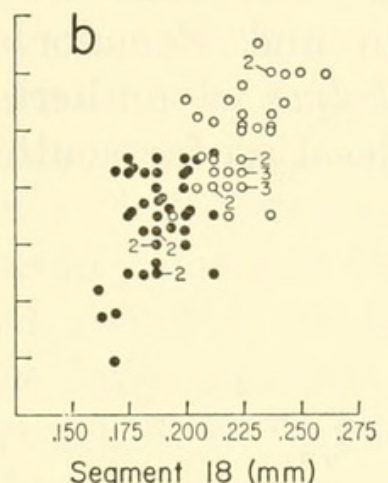

Segment $18(\mathrm{~mm})$

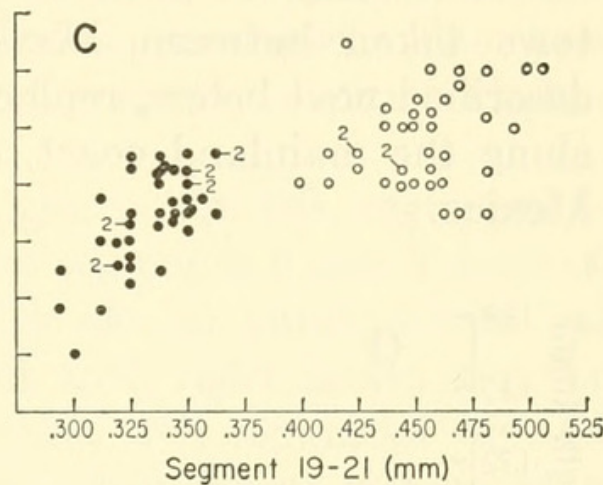

Figure 4.-Comparisons of selected structures in Labidocera jollae $\bigcirc$ and $L$. kolpos : $a-c$, length of adult male right A1 segments 17-21 plotted against length of prosome; $d$, maximum width of TV plotted against length of prosome in adult female. (Specimens chosen at random from selected localities.)

Coloration.-Preserved specimens (5 percent formaldehyde solution in sea water) exhibit two sets of carmine-colored structures, one between TI and TII, the other in TIII, as described above for jollae. The swimming legs also show a faint tint of blue in the cuticle. Living specimens were found to be uniformly blue-green as in jollae. Examination for chromatophores was carried out only on preserved material. The results suggest a chromatophore array similar to that in jollae but, due to fading of pigments, this should be confirmed by examination of living material.

Trpes.-Female holotype, USNM 110747, allotype, USNM 110748 , selected from material collected at station II-1 (lat. $28^{\circ} 03^{\prime} \mathrm{N}$, long. $111^{\circ} 16.5^{\prime} \mathrm{W}$ ), located a few yards offshore of a steeply sloped sand beach in a small cove, roughly 20 miles north of Guaymas, 
Sonora, Mexico. About 100 adult specimens collected with the holotype are deposited in the USNM, 110749. A series of reference specimens representing the known range in the Gulf of California has been deposited with SMIC XVIII-3.

Distribution.-Along the Mexican mainland the species has been taken from Puerto Peñasco to Isla Macapule, just south of Topolobampo. On the Baja California shore of the Gulf the species has been collected from San Felipe south to Bahia San Carlos, located just north of Santa Rosalia. Within these geographical limits (fig. 11) kolpos has been found most frequently and in the greatest abundance in near-shore waters. The species has not appeared in samples from the southernmost third of Baja California. It is also absent in the tows taken between Mazatlán and Ecuador. A related species, described next below, replaces kolpos in southern Baja California and along the mainland coast, at least as far south as Puerto Vallarto, Mexico.
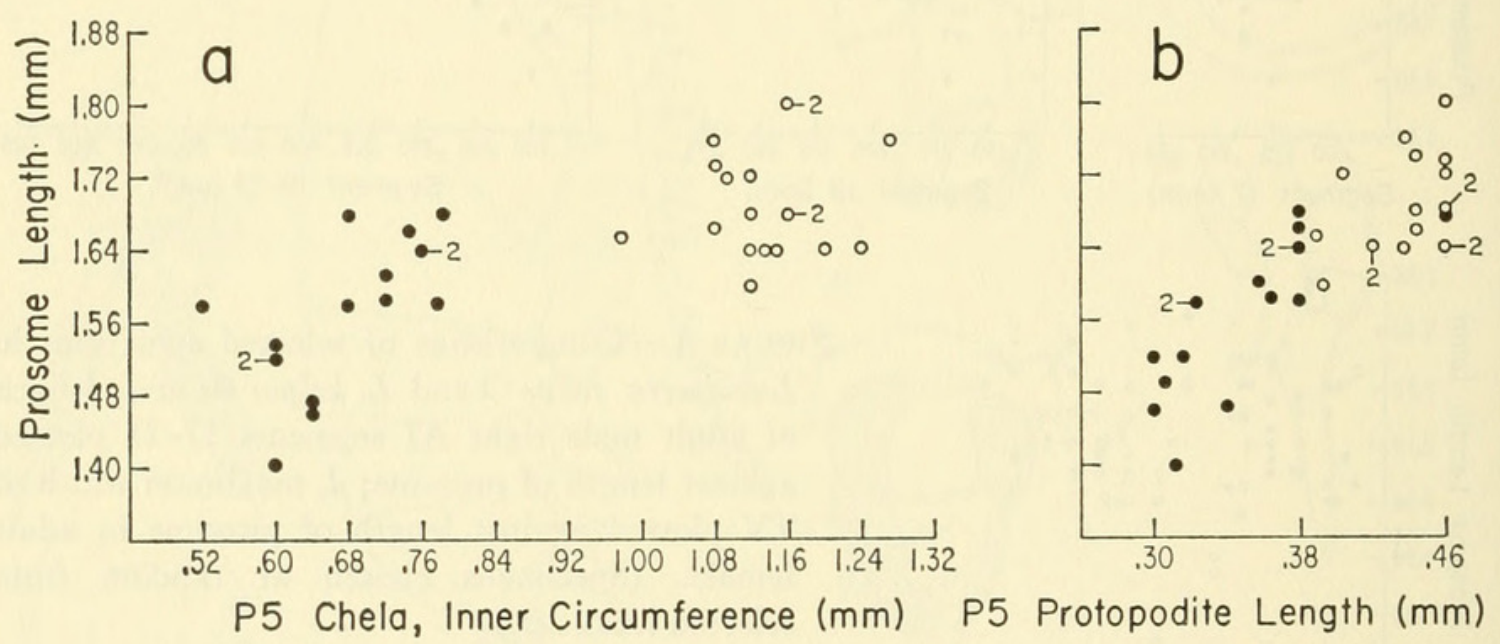

Figure 5.-Comparison of P5 in adult males of Labidocera jollae $\bigcirc$ and L. kolpos $\bullet$ chosen at random: $a$, length of inner circumference of chela plotted against prosome length (measurements of chela made with planimeter from camera lucida sketches of posterior view, $80 \times$ magnification; circumference limits are from apex of distal segment to apex of lateral prong of proximal segment); $b$, length of protopodite plotted against prosome length (protopodite measured along lateral margin at $80 \times$ magnification).

\section{Labidocera diandra, new species}

Figures 6-10

Localities, materials.-See table 3.

LENGTH AND BODY PROPORTIONS.-Adult and stage V copepodite measurements, excluding caudal setae, of specimens selected at random are as follows: 


\begin{tabular}{|c|c|c|c|c|c|c|}
\hline \multirow[b]{3}{*}{ adult $\subsetneq$} & \multirow[b]{2}{*}{ no. } & \multicolumn{3}{|c|}{ Total Length (mm) } & \multicolumn{2}{|c|}{$\begin{array}{c}\text { Prosome-Urosome Length } \\
\text { Ratio }\end{array}$} \\
\hline & & $m e a n$ & range & st. der. & median & range \\
\hline & 144 & 2.95 & $2.57-3.49$ & 0.140 & $3.5: 1$ & $3.1-4.0: 1$ \\
\hline adult $\sigma^{\top} \mathrm{A}$ & 135 & 2.95 & $2.53-3.25$ & 0.148 & $3.3: 1$ & $3.0-3.8: 1$ \\
\hline adult $\sigma^{x} \mathrm{~B}$ & 122 & 2.89 & $2.51-3.25$ & 0.152 & $3.4: 1$ & $2.9-4.1: 1$ \\
\hline st. V cop. $q$ & 25 & 2.13 & $2.00-2.32$ & & $3.6: 1$ & $3.4-3.9: 1$ \\
\hline st. V cop. A $\sigma^{7}$ & 25 & 2.12 & $1.93-2.31$ & & $3.4: 1$ & $3.2-3.7: 1$ \\
\hline st. $V$ cop. B $\sigma^{7}$ & 25 & 2.09 & $1.91-2.24$ & & $3.4: 1$ & $3.0-3.6: 1$ \\
\hline
\end{tabular}

Diagnosis.-Distinguished from other species by (1) details of sexually modified structures, (2) secondary loss of head-hooks in the mature stage of both sexes, and (3) occurrence of two morphologically different kinds of adult male (morph $\mathrm{A}$ and morph $\mathrm{B}$ ), the differences being concentrated in sexually modified appendages. The name diandra [Greek] refers to the two morphologically distinct kinds of males comprising this new species.

Adult A1 segments $24-25$ fused as in genus (fig. $6 d$ ), segments $8-9$ imperfectly fused as in jollae and kolpos; segments 6 and 7 perfectly separate. Forehead rounded, no head-hooks in adult, dorsal subcuticular eye lenses large in male, left and right lenses touching (fig. 8k); dorsal eye lenses in female small, well separated (fig. 6d). TIV and TV not fused. Rostrum as in jollae except lacking asymmetry in male (fig. 10a).

Adult female: TV in dorsal view produced posteriad in subequal lobes; in lateral view lobes flanking proximal end of genital segment (figs. $6 e, f$ ), reminiscent of detruncata; robust prong ventral to right lobe and extending posterolaterad (figs. $6 d, f$ ), left side of TV without prong. Urosome asymmetrical, in dorsal view with relatively long genital segment curving to right; anal segment small; caudal rami asymmetrical, left ramus larger, second innermost seta moderately expanded in proximal portion (fig. $6 d$ ). Genital segment with robust hooked process extending from anterior portion of left side (figs. $6 d, e)$; posterodorsal portion of genital segment with swollen dorsal surface lightly sculptured. Genital pore displaced to right of midlongitudinal axis (fig. $6 f$ ).

P5 with apex of exopod deeply bifurcated, weakly asymmetrical, right exopod longer; one or two small, lateral denticles occasionally present on exopod; endopods asymmetrical, left endopod apically bifurcated, right endopod spinelike with minute lateral prong (fig. $6 b$ ).

Adult male: Both male forms essentially identical in prosome and urosome; TV corners symmetrical with simple rounded margins not flaring outward (fig. 7c). Caudal rami elongate, length exceeding combined lengths of preceding three urosomal segments (fig. 8j). Forehead rounded, lacking head-hooks and crest (fig. $8 k$ ). 
Right A1 in dorsal view with segment 17 lacking denticulated ridge, anterior surface rounded, not flattened, and bearing small, low protuberance just proximal to midlength of segment. Segment 18 with prominent denticulated ridge; ridge extended proximad, projecting along axis of antennule and in dorsal view overlapping

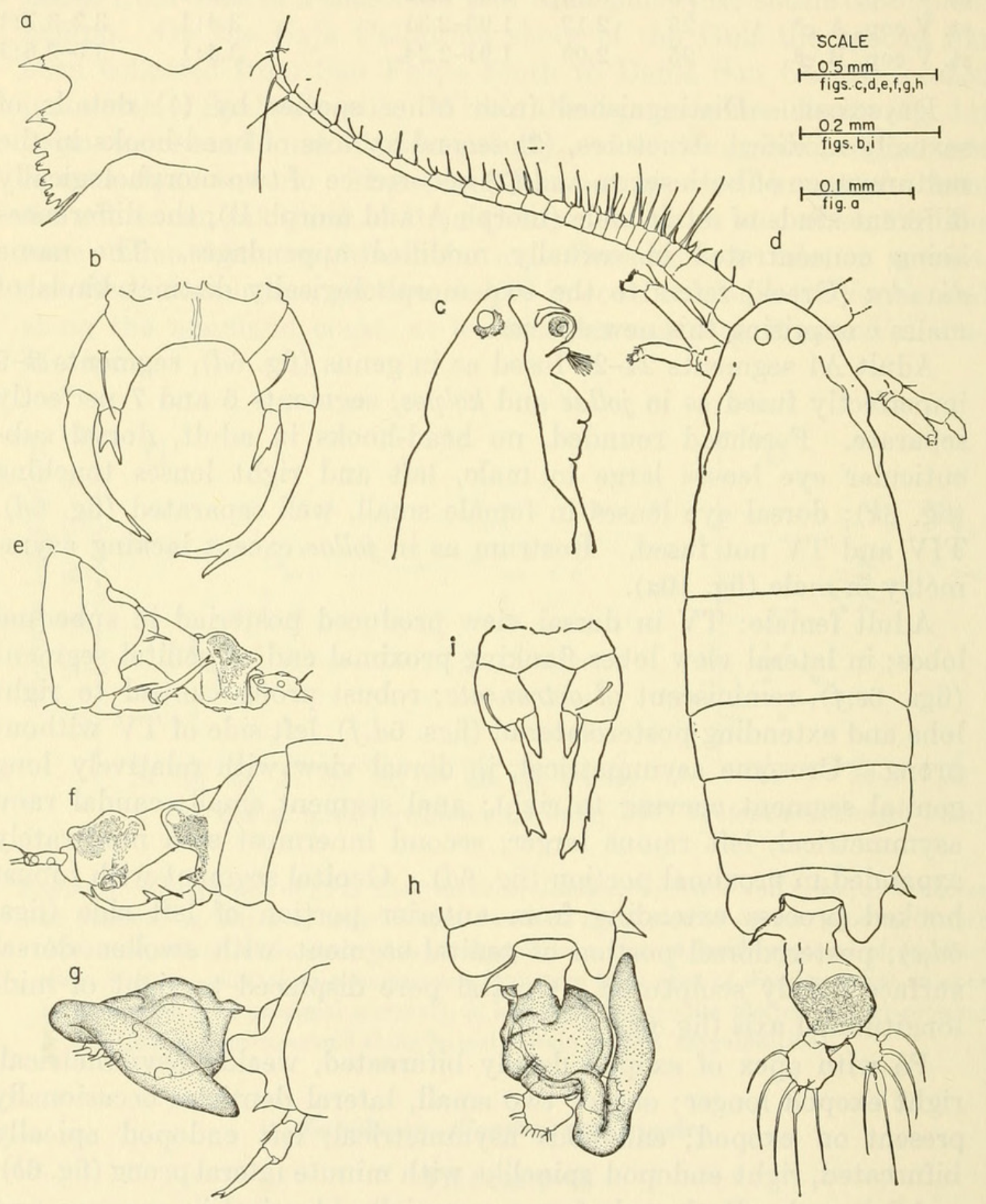

Figure 6.-Labidocera diandra, new species, adult female: $a$, right mandible, gnathobase, anterior view; $b, \mathrm{P} 5$, posterior view; $c$, cephalosome, right lateral view; $d$, prosome and urosome, dorsal view; $e$, posterior half of body, left side; $f$, posterior half of body, right side; $g$, posterior half of body, right side, with spermatophore; $h$, posterior half of body, dorsal view, with spermatophore. Penultimate copepodite: $i, \mathrm{P} 5$, posterior view. 
anterior edge of preceding segment, surface abutting segment 17 not flattened. Fusion segment 19-21 with well-developed denticulated ridge extending length of segment. Segment 22 with distal spiniform process about as long as segment 23 , in dorsal view process somewhat appressed to front edge of segment 23.

P3 and P4 asymmetrical, right leg with Se1 of Re1 and Re2 enlarged and extending perpendicular to axis of leg (figs. $7 g, 8 i$ ); in right lateral view enlarged spines (Se1) of P3 and P4 projecting obliquely posteriad (fig. $7 c$ ); $\mathrm{P} 3$ with Se1 of $\mathrm{Re} 2$ bearing large irregular lamella on distal border, Se1 usually coated with amber colored material resembling resinous (cement-like) secretion occurring on females where spermatophore is fixed to urosome.

Basic characteristics of $\mathrm{P} 5$, as in jollae and kolpos, are short left leg; long, robust right leg bearing large, ovate chela; left leg with terminal segment lacking prominent spines and processes, terminal segment roughly perpendicular to protopodite; ventral face hirsute; in general, left P5 also reminiscent of that in L. mirabilis (Fleminger, 1957, figs. 32, 33).

Morph A differs from morph $\mathrm{B}$ in details of the right $\mathrm{A} 1$ and chela of right $\mathrm{P} 5$.

Morph A: Right A1 with denticulated ridge of segment 18 extending proximad on an elongated process that reaches distal half of fusion segment 13-14 (fig. 7a). Segments of chela slender, elongated; proximal segment with perpendicular digitiform process extending from proximal end; process bearing knob on posterior face, ridge on anterior face. Slender distal segment (finger) opposes proximal segment (thumb), and closure of chela provided by finger crossing digitiform process of thumb (figs. $7 d-h$ ). Proximal segment of chela with large proximal seta; distal segment with three setae, one approximately one-third distance from origin of segment, second at midlength, third nearer apex.

Morph B: Segment 18 of right A1 with ridge extending proximad to suture between segments 16 and 17 (fig. $8 a$ ). Chela ovate, compact (figs. $8 d, e, h$ ), proximal segment roughly semicircular in lateral view and bearing a flaccid lamella with distal margin broadly notched; angle of lamella relative to segment varying from acute to perpendicular. Large seta originating at base of lamella resembling similarly positioned seta in male $\mathrm{A}$ and suggesting that lamella homologous to rigid digitiform process on proximal segment of chela in male A. Spinule located adjacent to distal side of lamella. Distal segment in ventral view somewhat lanceolate, with concave palmar surface opposing proximal segment; apex of distal segment terminating in small denticle; three setae on distal segment, one located close to 
origin of segment, one about one-fourth of length from origin, and one at midlength; number similar to those in male A.

Terminal segment of left P5 differing slightly in proportions from male $\mathrm{A}$ but similar in organization and armament (figs. $8 f, g$ ).

Additional description.-Cephalic appendages similar in most respects to Giesbrecht's (1892) account of L. wollastoni but showing several noteworthy differences. A2 with exopod almost as robust as endopod.

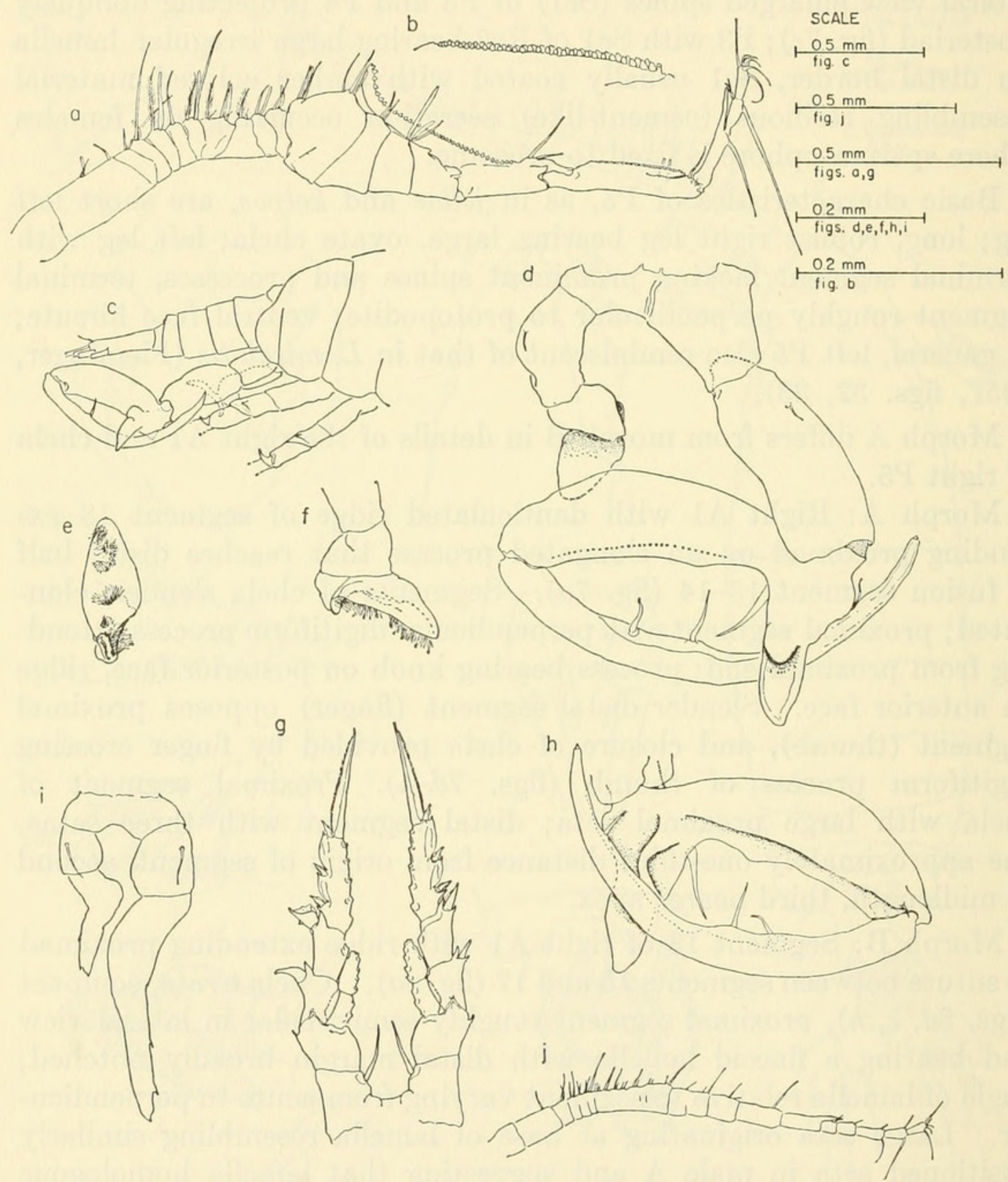

Figure 7.-Labidocera diandra, new species, adult male, morph A: $a$, right $\mathrm{A} 1 ; b$, dentition of fusion segment 19-21, right $\mathrm{A} 1 ; c$, posterior half of body, right side; $d, \mathrm{P} 5$, posterior view; $e, \mathrm{P} 5$, terminal segment of left leg, ventral surface; $f, \mathrm{P} 5$, terminal segment of left leg, lateral view; $g, \mathrm{P} 3$, posterior view; $h, \mathrm{P} 5$, chela, anterior view. Penultimate male: $i$, P5, posterior view (male $\mathrm{B}$ ); $j$, right $\mathrm{A} 1$, dorsal view (typical of both male forms). 


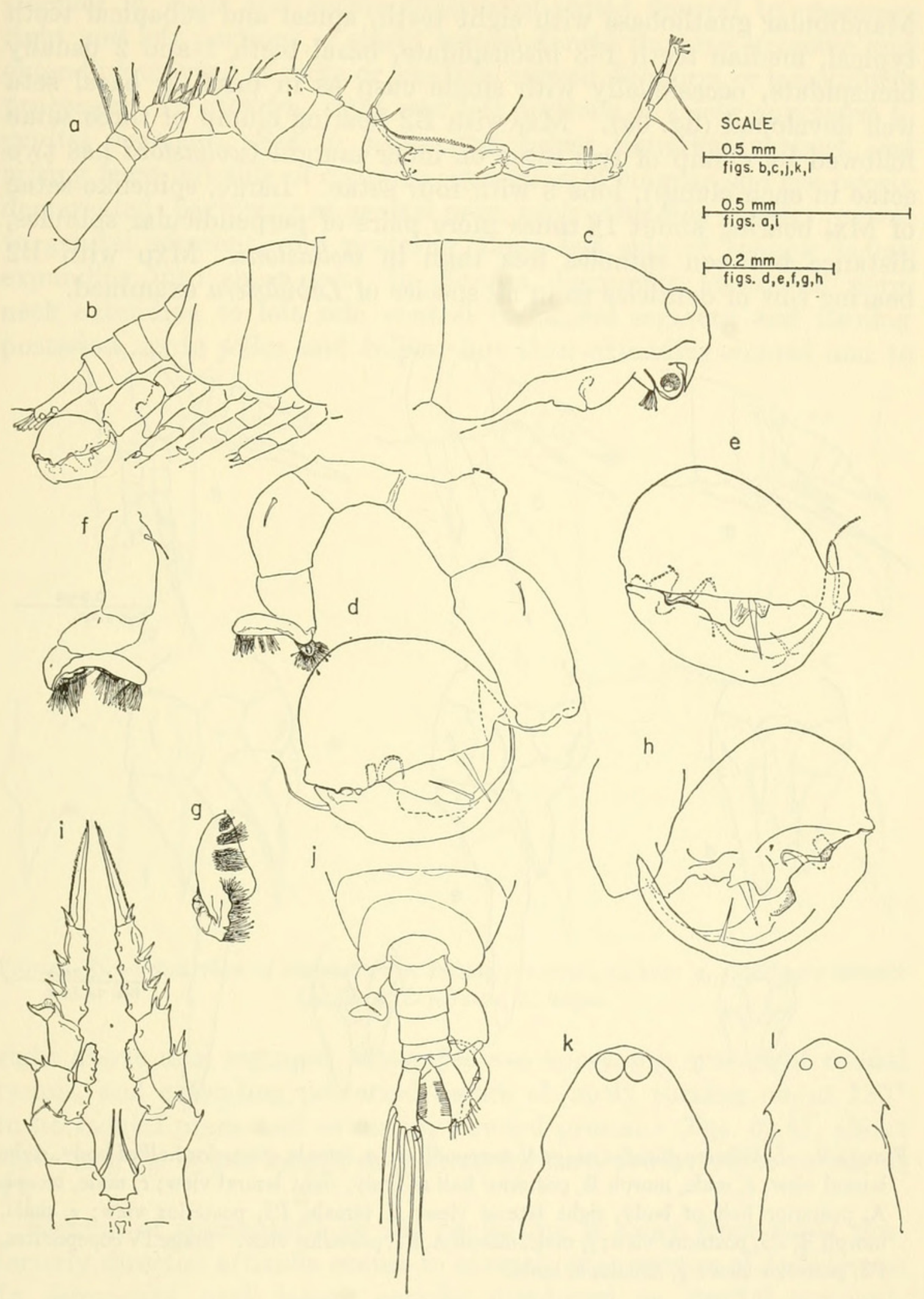

Figure 8.-Labidocera diandra, new species, adult male, morph B: $a$, right A1, dorsal view; $b$, posterior half of body, right side; $c$, cephalosome, right side; $d, \mathrm{P} 5$, posterior view; $e, \mathrm{P} 5$, chela, lateral view; $f, \mathrm{P} 5$, left leg, lateral view; $g$, $\mathrm{P} 5$, terminal segment of left leg, ventral surface; $h, \mathrm{P} 5$, chela, medial view; $i, \mathrm{P} 3$, posterior view; $j$, posterior half of body, dorsal view; $k$, forehead, dorsal view. Penultimate stage: $l$, forehead, dorsal view. 
Mandibular gnathobase with eight teeth, apical and subapical teeth typical, median teeth 1-3 biscuspidate, basal teeth 1 and 2 usually bicuspidate, occasionally with single cusp as in basal 3 ; basal seta well developed (fig. $6 a$ ). $\mathrm{Mx}_{1}$ with $\mathrm{B} 2$ bearing clump of three setae followed by clump of two setae on inner margin (wollastoni has two setae in each clump), lobe 3 with four setae. Large, spinelike setae of $\mathrm{Mx}_{2}$ bearing about $1 \frac{11}{2}$ times more pairs of perpendicular spinules, distance between spinules less than in wollastoni. Mxp with B2 bearing row of denticles as in all species of Labidocera examined.
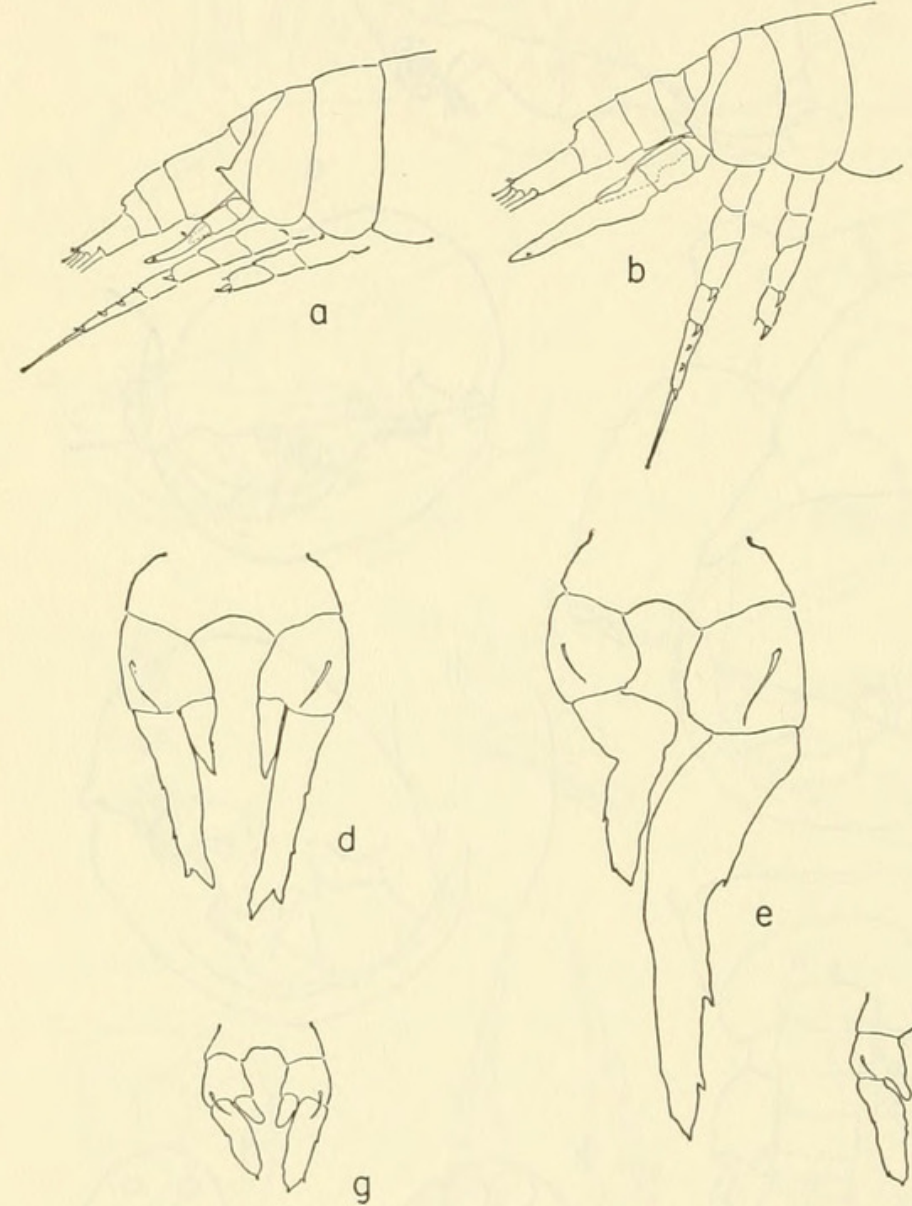

g

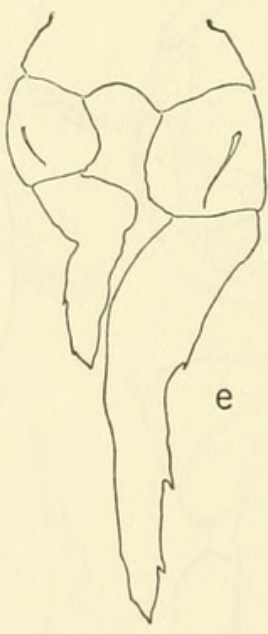

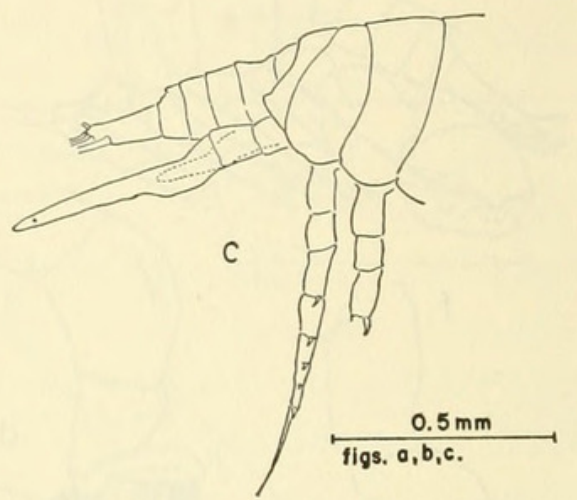

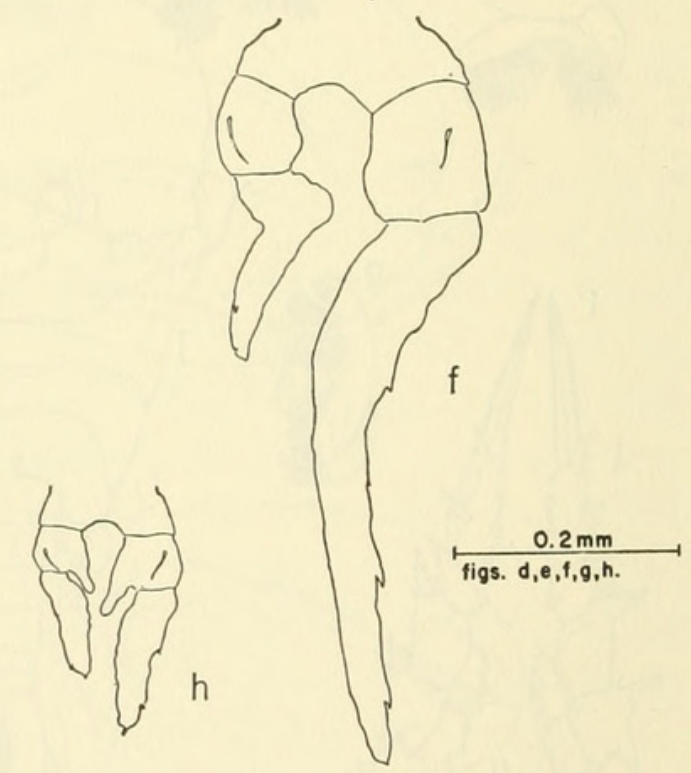

FiguRe 9.-Labidocera diandra, stage $\mathrm{V}$ copepodites: $a$, female, posterior half of body, right lateral view; $b$, male, morph $\mathrm{B}$, posterior half of body, right lateral view; $c$, male, morph $\mathrm{A}$, posterior half of body, right lateral view; $d$, female, P5, posterior view; $e$, male, morph B, P5, posterior view; $f$, male, morph A, P5, posterior view. Stage IV copepodites, $\mathrm{P} 5$, posterior view: $g$, female; $h$, male.

In adult female, tissue within right TV corner and ventral prong granular; lobe flanking genital segment with large clear space. Tissues underlying tergum of genital segment also glandular in appearance.

Spermatophore in diandra essentially similar to that in jollae and kolpos but differing in several fundamental characteristics from that in other coastal species of east Pacific Labidocera (Fleminger, 1964a). 
Coupler in jollae and kolpos consists of shield ventral to urosome; right and left portions of shield turned dorsad flanking urosome and extending upward as more or less free, curved, lobiform or lamelliform processes. In diandra, right and left portions of shield appressed to genital segment. Sac in jollae and kolpos remarkably short and arising from left side of coupler; separation of coupler and sac poorly demarcated; beginning at genital pore, neck extending to left, ventral to genital segment, and posterior along left side of coupler before expanding into short sac. In diandra, beginning at genital pore, neck extending to left side ventral to genital segment and turning posteriad, as in jollae and kolpos, but then extending dorsad and to

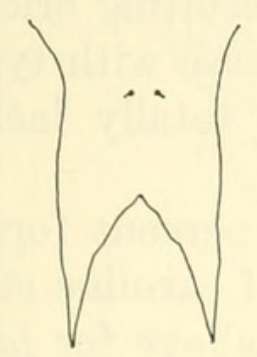

a

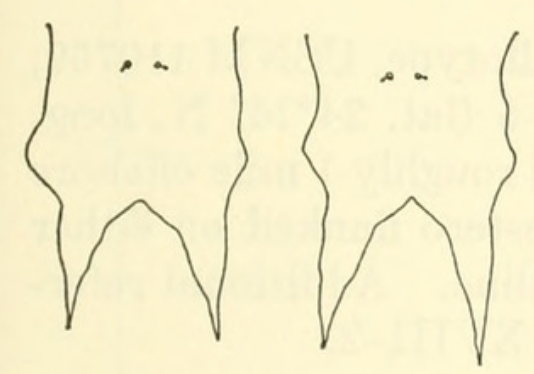

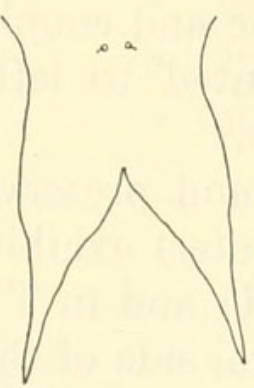

b

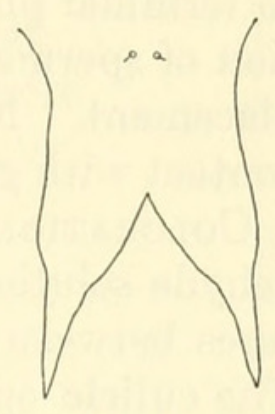

C
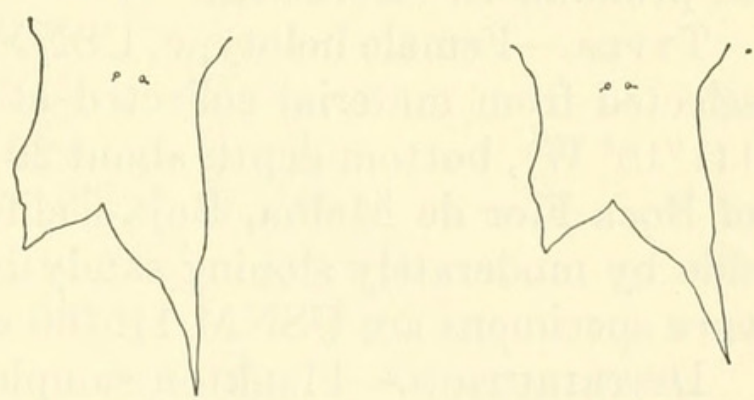

Figure 10.-Front view of rostrum (top, females; bottom, males): a, Labidocera diandra (A, B); b, L. jollae; $c$, L. kolpos.

right above anal segment; elongated sac appearing over right caudal ramus, and extending posteriad before abruptly turning about $180^{\circ}$ in horizontal plane and extending toward prosome (figs. $6 g, h)$; about three-fourths of sac length projecting forward toward right corner of TV.

Flexure of spermatophore sac projecting it away from usual posteriorly directed attitude occurs in several other species of Labidocera. In detruncata, neck leaves coupler middorsal on genital segment, broadening into sac and turning horizontally counter-clockwise about $150^{\circ}$, distal portion of sac extending to right more or less perpendicular to longitudinal axis of urosome. In acutifrons, neck bending abruptly about $180^{\circ}$ under left caudal ramus and sac projecting anteroventrad to left of urosome. In minuta, neck extending to left of midventral 
genital pore, turning posteriad and crossing ventral to anal segment to right side of urosome; portion of sac free of coupler extending anterolaterad.

Two types of spermatophore placement observed in diandra: type 1 placement considered normal; type 2 placement less common and appears to be nonfunctional. In type 1 , described above (figs. $6 g, h$ ), coupler envelops genital segment posterior to hook on left side and extends back to cover anal segment. Actual site of attachment of neck not observed but appears to emanate from genital pore.

Type 2 placement with spermatophore similar to that in type 1, but coupler cemented to left corner of $\mathrm{TV}, 180^{\circ}$ bend in sac anterior to terminal portion of sac which extends posteriad; resulting orientation of spermatophore sac and coupler $180^{\circ}$ out of phase with type 1 placement. Neck cemented to left corner of TV, totally lacking contact with genital pore.

Coloration.-Living and preserved specimens (5 percent formaldehyde solution in sea water) exhibit the same sets of carmine structures between TI and TII and in TIII as described above for jollae. The cuticle on the ventral side of the prosome and on the swimming legs is tinted blue. Otherwise the species is translucent and shows no pronounced coloration.

Types.-Female holotype, USNM 110758, allotype, USNM 110759, selected from material collected at station $\mathrm{F}-5$ (lat. $24^{\circ} 14^{\prime} \mathrm{N}$, long. $111^{\circ} 18^{\prime} \mathrm{W}$ ), bottom depth about $20 \mathrm{~m}$, located roughly 1 mile offshore of Boca Flor de Malba, Baja California, an estero flanked on either side by moderately sloping sandy beach coastline. Additional reference specimens are USNM 110760 and SMIC XVIII--2.

Distribution.-Plankton samples containing $L$. diandra (table 3 ) were collected in coastal waters usually within 1 mile of shore. The northernmost positive station $(\mathrm{F}-5)$ is located on the Pacific coast of Baja California just south of Almejas Bay $\left(24^{\circ} 20^{\prime} \mathrm{N}\right)$. Along the Gulf of California coast of Baja California, the species occurred as far north as Santa Rosalia $\left(27^{\circ} 19^{\prime} \mathrm{N}\right)$. From the eastern shore on the Mexican mainland we have four records, all coastal and from the region between Banderas Bay $\left(20^{\circ} 26^{\prime} \mathrm{N}\right)$ and Tenacatita Bay $\left(19^{\circ}\right.$ $\left.15.3^{\prime} \mathrm{N}\right)$. The distribution of $L$. diandra is shown in figure 11 . During portions of the year the range will probably be found to extend farther north (approximately a hundred miles) on both shores of the Gulf. The only remaining broad question of range concerns how far south the species extends along the Central American coast.

In general, the calanoids found in samples containing diandra were a mixed assemblage of coastal, neritic, and oceanic species which have a wide distribution in the eastern Equatorial Pacific. Samples rich in diandra were also rich in the coastal and neritic species of this 
assemblage, but the actual composition varied somewhat from tow to tow. Perhaps the only consistent feature is the relatively high abundance of inshore coastal species such as Acartia tonsa. Most interesting is the observed trend in the occurrence of other species of

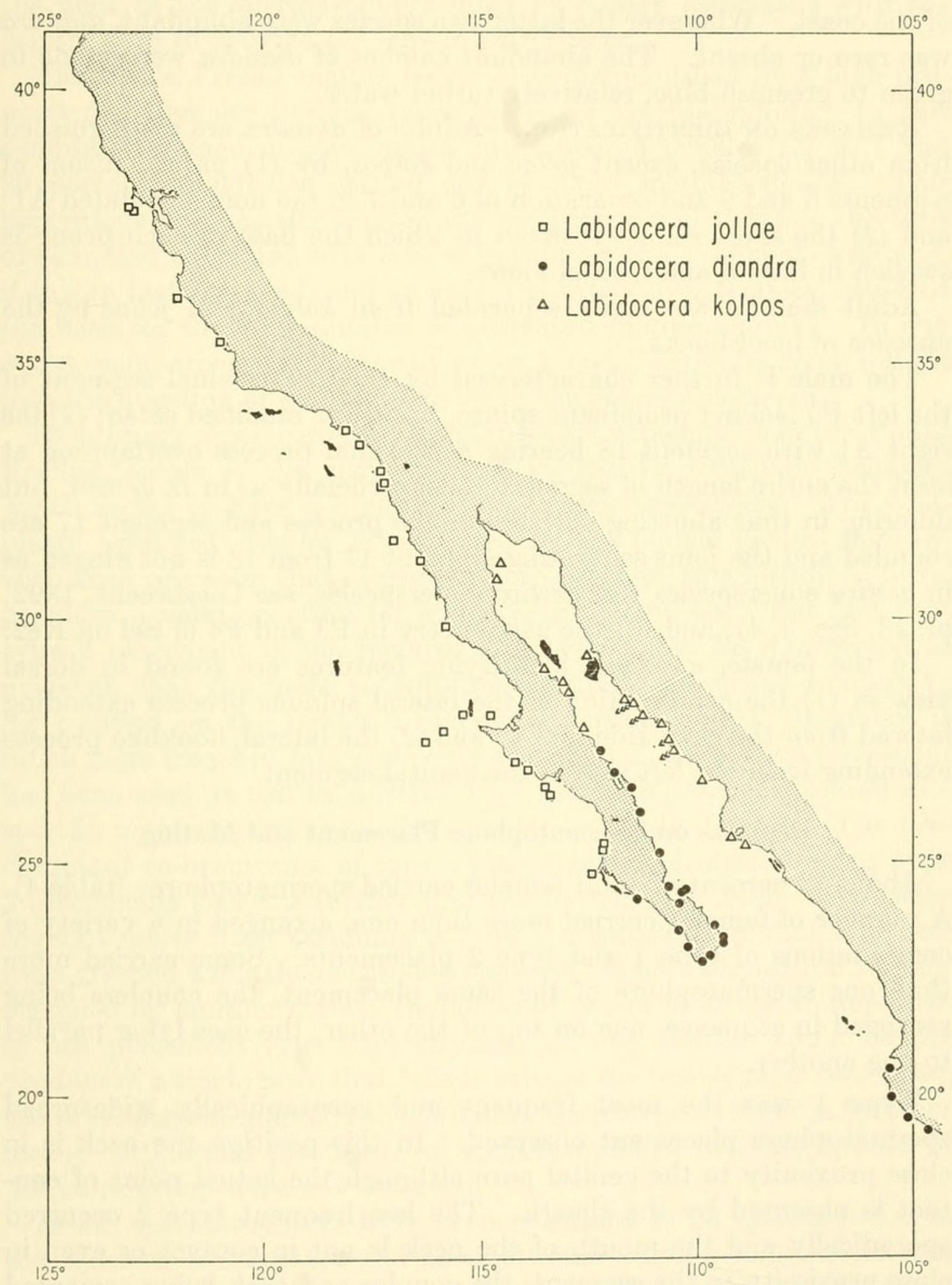

Figure 11.-Location of plankton samples containing species of the jollae group; no sample yielded more than one species. 
Labidocera. Within north-south limits of the diandra range, $L$. detruncata was very rare and decidedly offshore; $L$. acutifrons was abundant chiefly in the more offshore tows from blue, highly transparent water; and L. acuta was the numerically dominant species of the genus in blue to bluish-green water especially within 10-20 miles of the coast. Wherever the latter two species were abundant, diandra was rare or absent. The abundant catches of diandra were made in green to greenish-blue, relatively turbid water.

REMARKS ON IDENTIFICATION.-Adults of diandra are distinguished from other species, except jollae and kolpos, by (1) partial fusion of segments 8 and 9 and separation of 6 and 7 in the nongeniculated A1; and (2) the short robust rostrum in which the base of each prong is swollen in lateral and frontal views.

Adult diandra are easily separated from kolpos and jollae by the absence of head-hooks.

The male is further characterized by (1) the terminal segment of the left P5 lacking prominent spines, hooks, or modified setae; (2) the right $\mathrm{A} 1$ with segment 18 bearing a proximal process overlapping at least the entire length of segment 17 , superficially as in L. aestiva, but differing in that abutting surfaces of the process and segment 17 are rounded and the joint separating segment 17 from 18 is not hinged as in aestiva superspecies (for aestiva superspecies, see Giesbrecht, 1892, pl. 23, figs. 3, 4); and (3) the asymmetry in P3 and P4 of Sel on Re2.

In the female, excellent identifying features are found in dorsal view in (1) the combination of the lateral spinous process extending laterad from the right side of TV; and (2) the lateral, hooklike process extending from the left side of the genital segment.

\section{Remarks on Spermatophore Placement and Mating}

About 36 percent of adult females carried spermatophores (table 4). A number of females carried more than one, arranged in a variety of combinations of type 1 and type 2 placements. Some carried more than one spermatophore of the same placement, the couplers being arranged in sequence, one on top of the other, the sacs lying parallel to one another.

Type 1 was the most frequent and geographically widespread spermatophore placement observed. In this position the neck is in close proximity to the genital pore although the actual point of contact is obscured by the sheath. The less frequent type 2 occurred sporadically and the mouth of the neck is not in contact or even in close proximity to the segment, the coupler and neck being cemented to the left corner of TV.

In the material at hand, the frequency of type 1 spermatophore placement was more than three times that of type 2, and the latter, 
when present, usually occurrred in conjunction with a type 1 ; i.e., most specimens with a type 2 placement also carried another spermatophore in the type 1 position. Type 1 is, therefore, considered to be normal placement on the basis of higher frequency, more widespread occurrence, and the reasonable assumption that the opening to the neck of the spermatophore must be closely associated with the genital pore to provide the female with sperm.

The Punta Frailes sample (table 5) is distinguished by a high proportion of females bearing more than one spermatophore. In this sample, examined in toto, males outnumbered females 1.2 to 1 and 80 percent of females carried one or more spermatophores. This percentage is unusually high in my experience and suggests the time of sampling coincided with a local mating swarm. Sexual swarming, if this in fact occurred, and an excess of males over females, could be the basis for the large number of misplaced spermatophores. In any event, comparison of placement types 1 and 2 provides some insight into the question of sexual behavior in the genus Labidocera.

Of primary significance in spermatophore attachment in the Punta Frailes sample is the suggestion of instinctive ritualistic behavior which seems to have a high degree of species-specificity. The complexly arranged coupler is cemented to the female genital segment with such precision that spermatophore position, in addition to form, provides a valid criterion for identifying the species. The fact that type 2 placement is the reciprocal of type 1 can be interpreted as evidence that the male accomplishes coupler placement relative to his position on the female. Since the normal type 1 placement is much more frequent and since only one type of alternative placement has been seen, it can be inferred that the male positions himself in a specific manner relative to the orientation of the female. The predominant co-occurrence of type 1 placements on females bearing type 2 placements suggests further that the former type either deters subsequent males from assuming a type 1 orientation or that a second male grasped a female on the side opposite the normal position already occupied by another male. Instances of two or more spermatophores of one placement type superimposed on one another could be the product of a single male that fails to release the female after cementing the first spermatophore or the outcome of subsequent matings by other males. Abnormal placement of spermatophores in other species of the jollae group were not observed.

In all, spermatophores have been examined in 15 species found in the Western Hemisphere and an additional number from Africa and Asian coastal waters (Fleminger, unpubl.). Each species was found to have its own characteristic coupler-sac morphology and placement. One notable point of interest is the fact that the greater the extent of 
range overlap between species, the stronger the interspecific differences in spermatophore morphology. For example in the jollae group, diandra, potentially in contact with both jollae and kolpos, has a surprisingly unique spermatophore, whereas the latter two are allopatric and show only weak differences in spermatophore morphology.

Complexity and species-specificity in spermatophore morphology and constancy in its orientation with respect to the female urosome are compelling reasons to anticipate ritualistic mating behavior in the genus. Labidocera jollae has been observed briefly in copula on two occasions, once in January 1962 (pers. comm., Dr. Bui Thi Lang, SIO) and again in April 1964 (by the author). At first the two individuals were side by side. They quickly changed positions, pivoting about the region of the genital segment like the hands of a clock and causing the prosomes to be pointed in opposing directions while the urosomes crossed at about the level of the genital segments. Clasping lasted for at least 10 minutes. In both instances the observers were unable to note whether a spermatophore was deposited. More extensive observations on copepod mating behavior, however, are available for other genera.

Hill and Coker (1930) provide considerable evidence of ritual associated with copulation as well as a critical time for spermatophore deposition derived from observations on mating in several species of freshwater cyclopoids. They found that, regardless of which female structure was initially grasped, the male would later shift its position until it had secured itself to the female's fourth pair of swimming legs; furthermore, in several species, adult males remained close to or clasped a late stage $\mathrm{V}$ female and waited for ecdysis, thus guaranteeing that the spermatophore would be implanted on unhardened cuticle. Fahrenbach (1962) found a pronounced mating ritual in the algaldwelling harpacticoid Diarthrodes cystoecus, while Gauld's (1957) brief notes on mating in some estuarine-coastal planktonic calanoids (Centropages, Temora, Eurytemora, and Acartia) also suggest ritual prior to attachment of spermatophore and uniformity of orientation of the male during attachment.

In Pseudodiaptomus euryhalinus and $P$. coronatus, copula persists for hours and even days, whereas in Acartia tonsa the act is apparently accomplished in less than a minute (Johnson,1948; Jacobs, 1961). Jacobs (ibid., p. 445) observed that males were more prone to attack "when they chanced to become situated some $5 \mathrm{~mm}$ obliquely behind a female, leaving the impression that the attack might be triggered by the female feeding current." Johnson (op. cit.) noted that when isolated Pseudodiaptomus males and females are brought together a high percentage of the animals may copulate within a few minutes. 
The suggestion that the female feeding current triggers clasping by the Pseudodiaptomus male is not without merit; however, cephalic appendages appear to beat at relatively low frequencies. Underwater, low-frequency signals are probably subject to serious limitations for directionality and for separation from background noise. Such signals could be effective only over relatively short distances. Furthermore, no special organs of hearing are known in Crustacea (Cohen and Dijkgraaf, 1961).

Taking note of the commonness of cuticular pores overlying small epidermal glands, the abundance of aesthetasks on the A1 and the more extensive development of the latter in adult males of many families, it seems likely that mate recognition, pursuit and receptivity, the mating attack and locating of the female genital pore, etc., are mediated by chemical trail substances, i.e., pheromones. Feeding and swimming currents would serve to disperse these substances. Parker (1902), working on Labidocera aestiva, discusses several simple experiments which support the idea that the male finds the female by means of pheromones.

\section{Polymorphism in Labidocera diandra}

\section{Immature Copepodite Stages}

Head-Hooks.-Head-hooks of the usual form were seen in all immature copepodites (fig. $8 l$ ) from stages II to V. In copepodite stage I, found only in collections in and around La Paz Harbor, Baja California, in April 1962, both head-hooks and rostrum were absent. Except for the absence of head-hooks in adult diandra these findings agree with Johnson's (1935) account of rostrum and head-hooks in the ontogeny of L. jollae.

Regarding the ontogeny of other species of Labidocera, head-hooks are lacking in all stages of L. trispinosa, a fact established by Johnson (1935) and verified during the present study. For comparative purposes, I have also examined immature copepodite stages of other species of Labidocera at my disposal (table 6). No instance was found that paralleled the secondary loss of head-hooks ${ }^{3}$ seen in

${ }^{3}$ I have found two specimens of Labidocera in collections from Mombasa, Kenya (Lusiad Expedition, lat. $4^{\circ} 04^{\prime}$ S, long. $39^{\circ} 39^{\prime}$ E, VII-24-1962, tow 1, 1824-1829 hrs., tow 2, 1852-1859 hrs., 1/2 m net, 3-0 m depth) that agree in all particulars with $L$. kroyeri except that head-hooks are lacking. No younger copepodites, males or normal kroyeri females were present in the two samples. I have seen normal kroyeri in a collection from Ceylon (Lusiad Expedition, VIII-28-1962, 1807-1817 hrs., 1 m net, 3-0 m depth, in Colombo, Ceylon Harbor). Brady (1915) included kroyeri in a list of copepods from Durban Bay, South Africa, but failed to include notes on its appearance. 
diandra, but it should be pointed out that the list in table 6 represents less than half of the described species.

The presence or absence of head-hooks in pontellids, and especially in Labidocera, has been widely regarded as a feature of considerable taxonomic significance. Obviously, if head-hooks can vary in occurrence intraspecifically, their usefulness to phylogeny hinges upon a thorough survey of all species in the genus. Head-hooks are found in other pontellid genera (Anomalocera, Pontella, Calanopia, Ivellopsis, Epilabidocera) but not necessarily in all species of these genera. They are characteristically absent in two other genera (Pontellopsis, Pontellina). Based on this distribution, head-hooks may be regarded as an older generalized feature that is losing adaptive value in some of the younger phyletic lines. Certainly, revision of Labidocera is

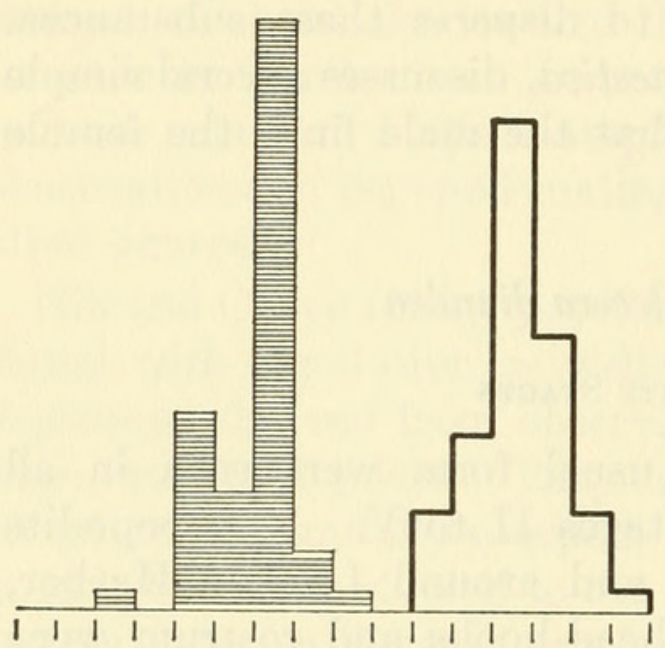

Labidocera diandra, O", St. $\mathbb{Z}$
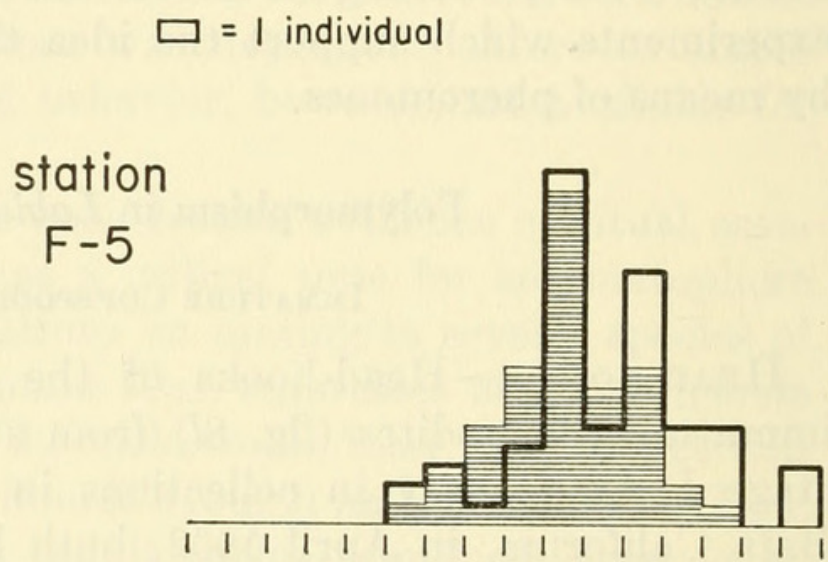

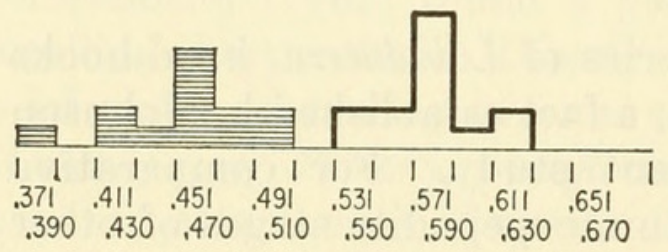

Right P5 Length $(\mathrm{mm})$ station
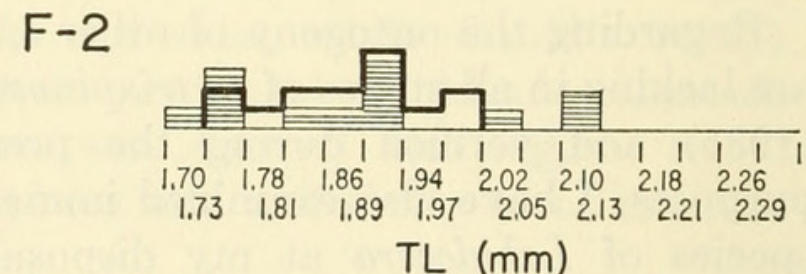

Figure 12.-Size distribution of right leg 5 (P5) and total length (TL) in male Labidocera diandra, stage V copepodites, collected at stations F2 and F5 (horizontal hatching= morph B males; heavy line=morph A males; specimens selected at random and measured at $60 \times$ magnification).

not merely a matter of grouping species according to (1) the presence or absence of head-hooks in adults and (2) urosomal segmentation in adult females, as suggested by Sewell (1956). Not only are headhooks undependable but the urosome is variously two and three segmented in head-hooked and nonhead-hooked species alike. 
P5.-In the stage V female the P5 exopod (figs. $6 i, 9 d$ ) bears three short, lateral, spinulose processes. The apex is spiniform and the left leg is slightly smaller than the right. The female P5 increases uniformly with subsequent moults, following appearance of the appendage in stage IV (figs. $9 g, 14$ ); lateral spinous processes on the exopod disappear in stage VI (fig. $6 b$ ).

\section{LABIDOCERA DIANDRA STAGE}

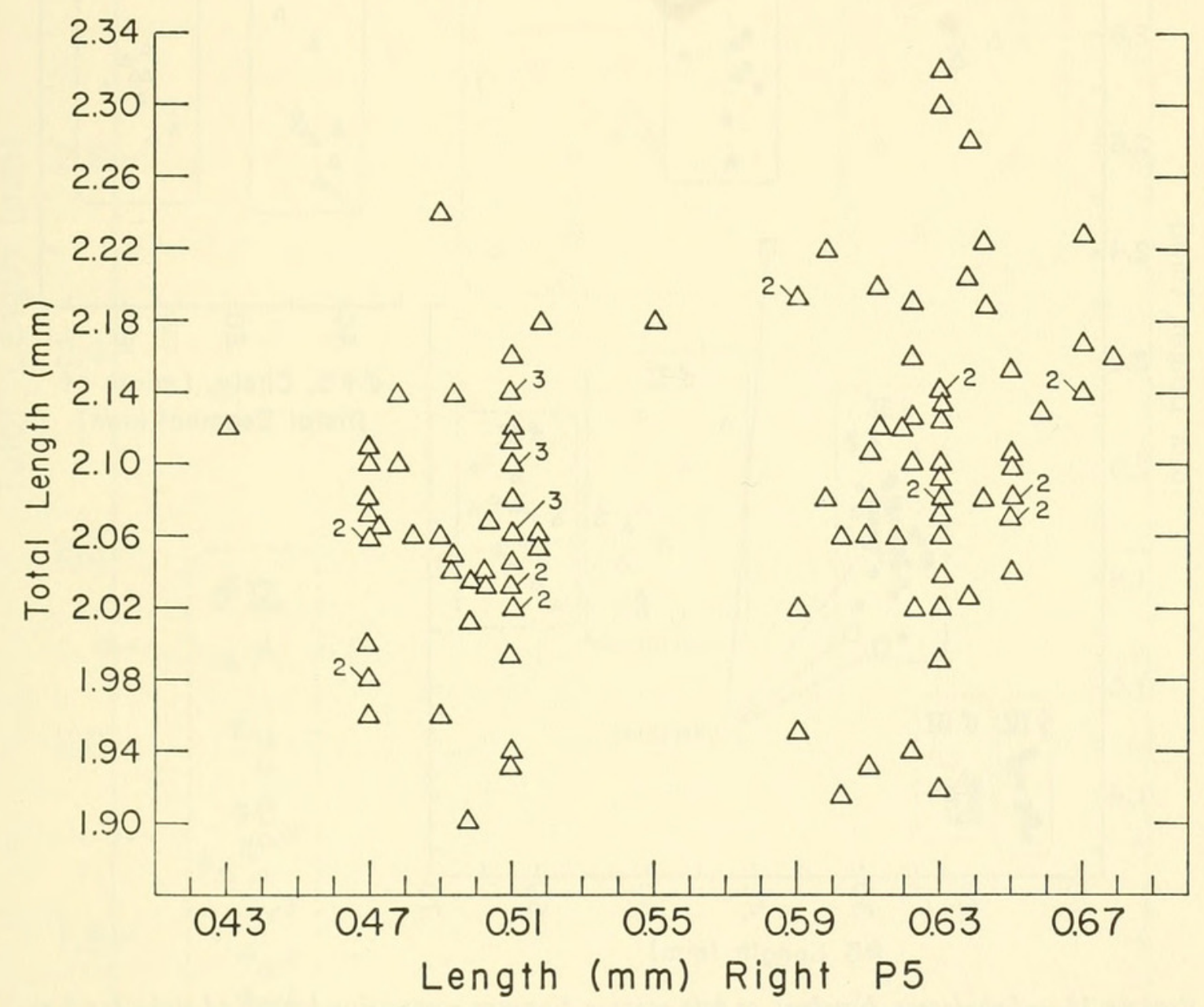

Figure 13.-Scatter diagram comparing length of right leg 5 and total length in male Labidocera diandra, stage $\mathrm{V}$ copepodites (measurements taken from lateral view at $62.5 \times$ magnification, using undissected specimens, appendage length extending from line of articulation of protopodite with tergite to apex of ramus; specimens selected at random from sample F5).

The stage V male P5 (fig. $7 i$ ) resembles that found in jollae in the arrangement of spinous processes and basic proportions. It differs in lacking rudimentary endopodal lobes and in having a knoblike protrusion on the median side of the left ramus.

Stage V males can be separated into two groups (morph 1 and morph 2) based on length of P5 (figs. $9 e, f$ ). This division, into a longer and 
a shorter length, occurs irrespective of the individual's TL (figs. 12, 13 , table 7). TL distribution among the two morphs differ only slightly and in the same direction and degree as morph A differs from morph B in adult males (table 8). P5 size distribution in stage IV males does not appear to be bimodal (fig. 14).

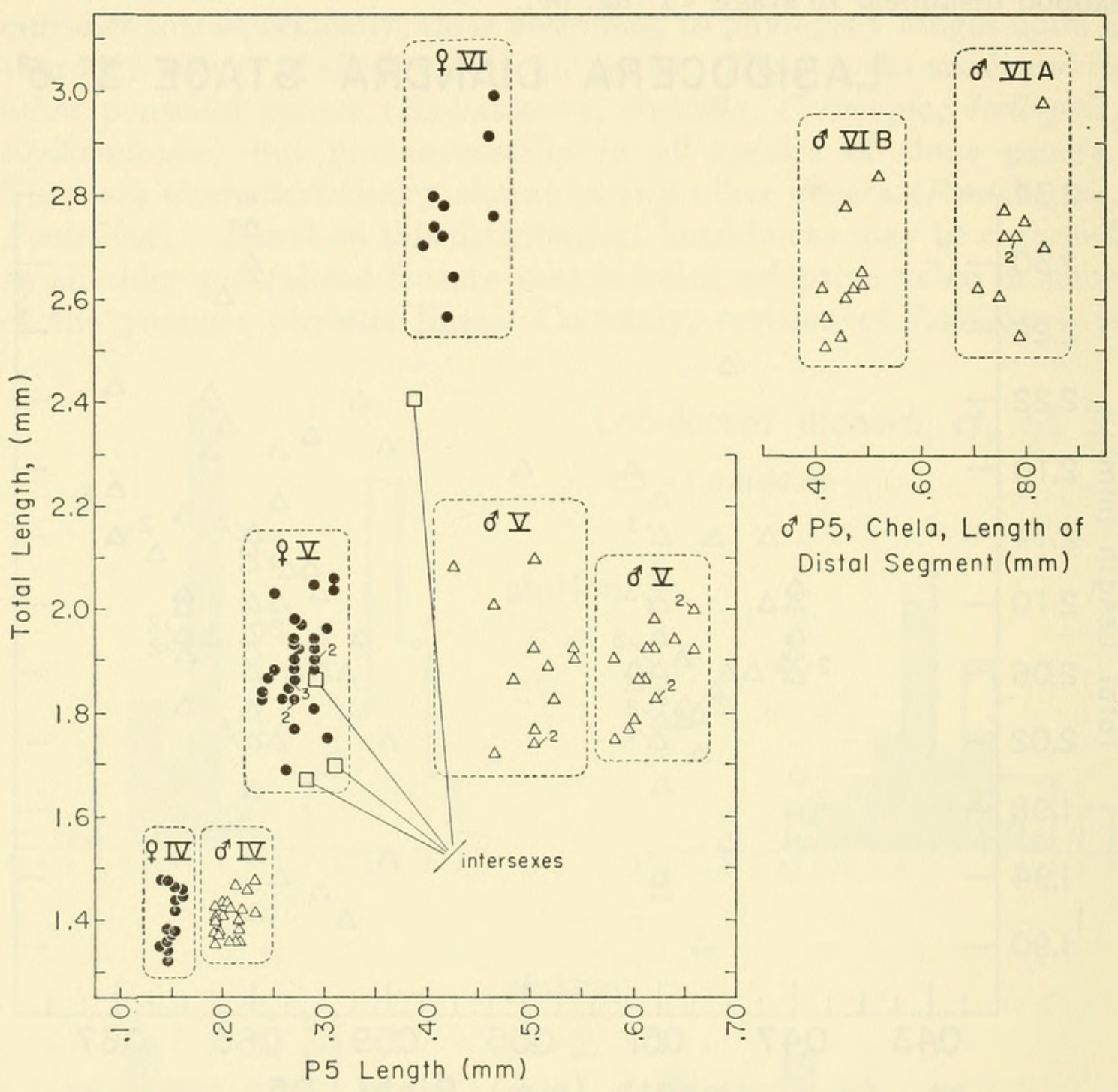

Figure 14.-Labidocera diandra: at left scatter diagram comparing length of right leg 5 to total length in male $\Delta$ and female $\boldsymbol{\bullet}$, stages IV and V copepodites and stage VI female; in upper right, scatter diagram comparing length of distal segments of chela with total length in stage VI male (chela measured by planimeter from camera lucida drawing of posterior view; segment length determined along inner perimeter relative to mouth of chela; specimens selected at random from station F2).

In the moult to stage VI, the terminal segment of right P5 divides to form the chela, the proximal segment becoming the thumb, the distal segment the finger. Assuming that the lateral spinous processes on this leg in stage $\mathrm{V}$ are homologous to setous-like spines in the adult chela, the proximal segment in the adult appears to be a fusion of $\operatorname{Re} 1$ and $\operatorname{Re} 2$, while the distal segment comprises Re3. Immature stages of female and male P5 are compared in figure 9. 


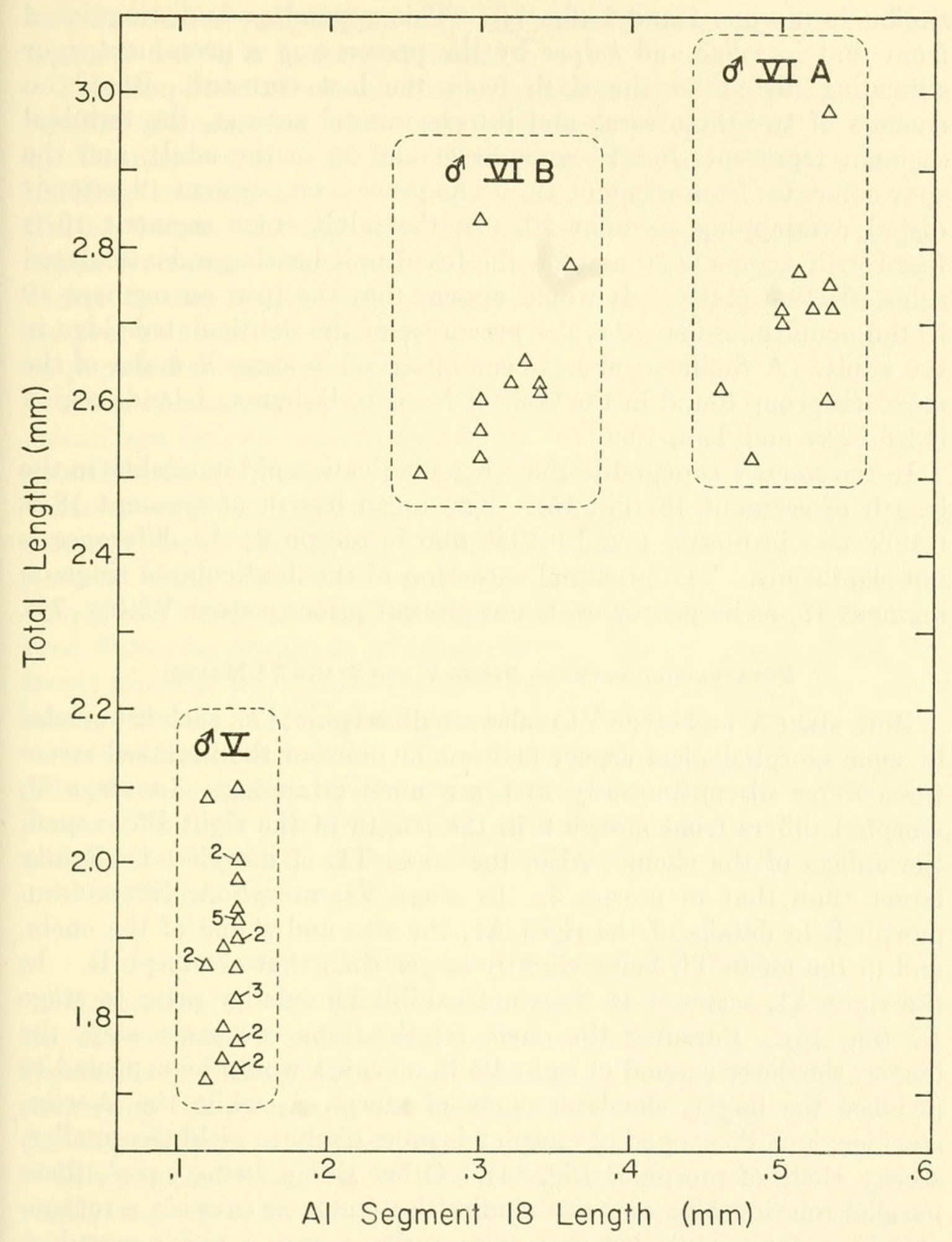

Figure 15.-Labidocera diandra: scatter diagram comparing total length to length of segment 18 of right antennule in male stages V and VI (length of segment 18 taken with planimeter from camera lucida drawings along anterior perimeter from apex of proximal process to distal limit of segment; specimens chosen at random from sample F2). 
Male Right antennule.- In the penultimate male the right A1 is similar in morphs 1 and 2 (fig. $7 j$ ). This appendage is distinguished from that in jollae and kolpos by the presence of a prominent spur extending distad on the sixth from the last segment. Based on clusters of two-three setae and intersegmental sutures, the terminal segment represents fused segments 24 and 25 in the adult, and the spur emanates from segment 19 . The process on segment 19 extends distad overlapping segment 20 . In the adult stage segment 19 is fused with segments 20 and 21 , the fused unit bearing a denticulated ridge (friction plate). It would appear that the spur on segment 19 in the penultimate stage is the precursor of the denticulated ridge in the adult. A similar spur has been observed in stage $\mathrm{V}$ males of the mirabilis group found in the Gulf of Mexico, Bahamas Islands region (Fleminger and Tan, 1966).

In the stage $\mathrm{V}$ copepodite there is no indication of bimodality in the length of segment 18 (fig. 15). The mean length of segment 18 is $0.1360 \mathrm{~mm}$ in morph 1 and $0.1358 \mathrm{~mm}$ in morph 2 ; the difference is not significant. The proximal extension of the denticulated ridge on segment 18, or its precursor, is not present prior to stage VI (fig. $7 j$ ).

\section{Relationship between Stage V and Stage VI Males}

Both stage V and stage VI males are dimorphic;i.e., each is bimodal in some morphological aspect and one or more of the involved structures differ discontinuously and are nonoverlapping. In stage $\mathrm{V}$, morph 1 differs from morph 2 in the length of the right P5 exopod, the anlage of the chela. Also, the mean TL of morph 1 is slightly larger than that of morph 2. In stage VI, morph A differs from morph $\mathrm{B}$ in details of the right $\mathrm{A} 1$, the size and shape of the chela, and in the mean TL being slightly larger than that of morph B. In the right $\mathrm{A} 1$, segment 18 does not exhibit bimodality prior to stage VI (fig. 15). Pursuing the chela relationships one more step, the longer, slenderer exopod of right $\mathrm{P} 5$ in morph 1 would be expected to produce the larger, slenderer chela of morph A, while the shorter, stockier right P5 exopod of morph 2 is more likely to yield the smaller, stocky chela of morph B (fig. 14). Other things being equal, these parallel relationships and size similarities (table 8) provide a reasonable basis for postulating that at maturity morph 1 yields morph $\mathrm{A}$ adults and morph 2 produces morph $\mathrm{B}$ adults.

There is no obvious agreement in the relative abundance of the morphs between stages $\mathrm{V}$ and VI (table 9). The ratio of stage V and stage VI morphs vary widely in individual samples and in the summed totals as well. This may not constitute a denial of the postulated relationship of the four morphs since genetic polymorphism provides the species with a rapid process for resolving adaptation 
to recurrent environmental fluctuations (see Ford, 1964, for examples and discussion). Evidence that the male morphs of diandra have a genetic origin is presented below.

Polymorphism of sexual structures in marine Calanoida is not a familiar phenomenon. One case presented in an unpublished thesis by Fleminger (1956) involves Pontella meadii, a surface species inhabiting transitional warm-temperate coastal waters of the eastern United States. In this area the offshore climate provides a yearround warming influence that is overcome to varying degrees in winter by the continental climate. The resulting seasonal changes are probably not too dissimilar to the variable conditions experienced by populations of $L$. diandra in the northern segment of its range and in areas of seasonal upwelling. Two forms of the adult male of $P$. meadii are known, one described by Wheeler (1900) and the other described as $P$. pennata by Wilson (1932). Regarding the female, Wheeler worked only with stage V copepodites and apparently assumed they were adult. Wilson described the adult female as pennata along with the larger sized male morph. More recently, Haq $(1960,1965)$ reported finding genetic polymorphism in laboratorybred Euterpina acutifrons (Harpacticoida). Two morphologically different kinds of adult male are described. Johnson (1964) found two kinds of male of Pseudodiaptomus wrighti which differ in several structural features including the size of the fifth pair of legs; however, only three examples of the morph with the larger fifth legs were observed in the hundreds of male specimens examined. In $L$. diandra and $P$. meadii both morphs are relatively common and occur throughout the range of the species.

\section{Deviation in the Sex Ratio in LABIDOCERA DIANDRA}

Comparison of the relative abundance of males and females in diandra revealed a conspicuous deviation in the adult stage from an expected 1:1 ratio (table 9). Abundance estimates were obtained by tabulating the species in the entire sample, excepting tow $\mathrm{F}-5$; for the latter a large subsample was counted.

Using pooled data stage $\mathrm{V}$ males and females do not differ significantly from a $1: 1$ ratio $\left(\chi^{2}=7.58, \mathrm{p}=0.025-0.020\right)$. In the adult stage, however, males exceed females by 1.0:0.69, the deviation from $1: 1$ being highly significant $\left(\chi^{2}=157.5, \mathrm{p}=<0.001\right)$. These relationships apply to summed data but not necessarily to values obtained from any single collection.

Despite extensive variation in the numbers of adults, males exceeded females appreciably in six of the seven large collections of the species. In the seventh (El Golfo station 24), males are too rare for the sample to be regarded as representative. Considerable variation in the rel- 
ative numbers of $\mathrm{A}$ and $\mathrm{B}$ males should also be noted since they conflict with the alternative that only one of the two males is conspecific with the female. If we assume that the two males are not conspecific and that the probable sex ratio approaches $1: 1$, to account for the quantitative data on hand requires an additional complicating assumption, namely, that there are two kinds of females that are morphologically indistinguishable (i.e., in the characters that have been examined). The two species alternative would have to provide for the co-occurrence of the two species over the same limited geographical range, when as a rule closely related species of Labidocera do not overlap extensively (Fleminger, unpubl.). Thus, this line of reasoning becomes burdensome without necessarily contributing to a better understanding of the extant data.

Assuming the diandra population as described above is conspecific, three facts stand in evidence that the dimorphism is under relatively simple and direct genetic control, namely: (1) dimorphism occurs throughout the range; (2) there is no intergrading of dimorphic characters; and (3) dimorphism is sex linked. These three points also prevail in the case of Pontella meadii referred to in the preceding section.

One hypothesis can account for both the basic features and variability of the unusual sex ratio in adults and the polymorphism in males. It requires the following assumptions: that the male is the heterogametic sex, that the gene (or polygene) controlling morph type is on the $\mathrm{X}$ chromosome, and that one class of homozygote females fails to achieve sexual maturity; hence, the frequency of adult males in a deme would reflect the local frequency of the $\mathrm{A}$ and $\mathrm{B}$ alleles and this, in turn, should agree with the ratio of adult females to males on the basis of the Hardy-Weinberg equilibrium.

The hypothesis also accounts for a 1:1 sex ratio in stage V copepodites. Presumably, the polymorphism is adaptive in that the heterozygote female conserves both alleles and the local population benefits in having the ability to rapidly shift its genotype to meet crucial changes in local environmental conditions. In some aspects the available data fit this model surprisingly well (table 9); however, the lack of concordance between adult and stage $\mathrm{V}$ morph frequencies and the overall sparseness of the data emphasize the need for more intensive collections representative of both range and seasonal fluctuations. Obviously, ultimate confirmation that genetic polymorphism is the basis for the observed facts will require breeding experiments.

\section{Relationship of the jollae Group to the Genus}

The three species described above are considered a species group, in the sense of Mayr (1963), as a consequence of sharing essential morphological similarities and occupying successive geographical 
ranges. Adults of this group show two characteristics which set them apart from the remainder of the genus, namely: (1) antennules with segments 8 and 9 partially fused; and (2) mandibular gnathobase with basal teeth 1 and 2 usually bicuspidate. The jollae group is further distinguished from their closest relatives, the mirabilis group (Fleminger and Tan, 1966) in the retention of head-hooks (except in adult diandra).

A large number of morphological features are shared exclusively by the mirabilis and jollae groups. This and their endemism in the Americas constitute a firm basis for combining them in the wilsoni superspecies as proposed by Fleminger and Tan, (1966). This superspecies is characterized by (1) short rostral prongs, which have a swollen proximal portion and are separated in frontal view by a triangular notch (fig. 10); (2) separation of TIV and TV; (3) twosegmented, asymmetrical urosome and usually asymmetrical caudal rami in the female; (4) male left leg 5 usually short, terminal segment padlike, densely pilose and bearing three minute spines or setae or none at all; (5) male lacking specialized outgrowths on right corner of TV; and (6) male with asymmetrical exopodal spines on one or more pairs of swimming legs. Also noteworthy is the strong overall similarity of immature stages, especially in such critical features as the fifth legs and rostrum and the crimson bodies in the thorax.

Other head-hooked species differ from the jollae group in having (based on various sources including unpublished observations of the author) (1) relatively long, slender rostral prongs; (2) nongeniculated antennule segmentation numbering $24(24-25$ fused) or, if 23 , with 6-7 and 24-25 fused; (3) female with three-segmented urosome; (4) male left leg 5 more than one half the length of right leg 5 , terminal segment of former with several robust spiniform or setiform processes, conspicuous and often incompletely fused to segment; (5) male TV usually asymmetrical, right posterior corner being variously modified; and (6) male right antennule with segment 17 bearing modified seta anteriad, more or less ridgelike.

The wilsoni superspecies shows morphological affinities with another assemblage of predominantly Indo-Pacific species of which $L$. detruncata is characteristic. This resemblance is restricted to a few structures modified by secondary sexual development and lacks the support of similarities in rostrum configuration and $\mathrm{A} 1$ segmentation. In reviewing the genus, division of the species among groups and superspecies has proven most helpful and provisional monophyletic aggregations are given below.

Superspecies wilsoni (coastal, temperate to subtropical).

jollae group: L. jollae Esterly, diandra, new species, kolpos, new species (west coast, North America). 
mirabilis group: L. mirabilis Fleminger, wilsoni Fleminger and Tan (southern Florida, Bahama Islands).

Superspecies detruncata (mostly tropical, neritic or island forms of Indo-Pacific):

L. detruncata (Dana) (Indo-Pacific, oceanic), orsinii Giesbrecht, gangetica Sewell, cervi Krämer, caudata Nicolls, bataviae Scott, madurae Scott, pavo Giesbrecht, species Farran (1936) (Indo-Pacific, neritic-island forms), nerii Kröyer (Atlantic, oceanic).

Superspecies darwinii (predominantly neritic):

trispinosa group: L. trispinosa Esterly, johnsoni Fleminger, lubbockii Giesbrecht (western American coast).

ungrouped species: L. darwinii Lubbock (southeastern South America), fluviatilus Dahl (eastern South and Central America), aestiva Wheeler (eastern North America), species (in preparation, subtropical-tropical America), scotti Giesbrecht (west Africa), brunescens Czerniavski (Mediterranean, west Africa), acutifrons (Dana) (subtropical panoceanic).

Superspecies kroyeri (predominantly neritic, Indo-Pacific): L. kroyeri (Brady), pectinata Thompson and Scott, bipinnata Tanaka, japonica Mori, minuta Giesbrecht, bengalensis Krishnaswamy, rotunda Mori, species Dakin and Colefax (1940).

Unassigned species (predominantly neritic): L. glauca Smith (Philippines), laevidentata (Brady) (Indo-Pacific), euchaeta Giesbrecht (Indo-Pacific), wollastoni (Lubbock) (western European coast, Mediterranean), acuta (Dana) (Indo-Pacific).

Species based on immature stages, or otherwise doubtful: L. simplex (Dana), crispata (Dana), exigua (Dana), frivola (Dana), media (Dana), hebes (Dana), inermis Brady, chubbi Brady, agilis (Dana).

\section{Relationships Within the jollae Group}

The jollae group is geographically isolated from the mirabilis group as well as from other head-hooked species of the genus. As shown above, the group is indigenous to coastal waters of western North America. The three species of the group succeed each other geographically, each occupying a biogeographically distinct portion of the coastline from California to Mexico. L. jollae is found in temperate waters off California and northern Baja California. $L$. diandra occurs in the subtropical waters of southern Baja California and further south along the Mexican mainland. L. kolpos is isolated in the upper half of the Gulf of California where conditions are often unusually warm but must be regarded as temperate for year-round residents (Hubbs, 1948; Roden, 1958, 1964; Roden and Groves, 1959); hence, the two temperate species are allopatric, but, independently, the range of each extends south to the northern limits of diandra.

Considering range relationships, character differences (Schoener, 1965) in TL (fig. 16) and PUR (fig. 17) deserve closer examination. Turning first to the allopatric pair, jollae and kolpos, TL and PUR values are remarkably similar. In the male sex, jollae exceeds kolpos in TL by about 7 percent (difference between means, Student $t$ test, 
$\mathrm{p}<.001)$. Differences between the sexes, however, are much more conspicuous (table 10). In fact, using mean TL values, males are 16 percent (jollae) and 21 percent (kolpos) smaller than their respective females. In PUR the median ratio in males is about 30 percent smaller than in females in both species. The urosome is, in general,
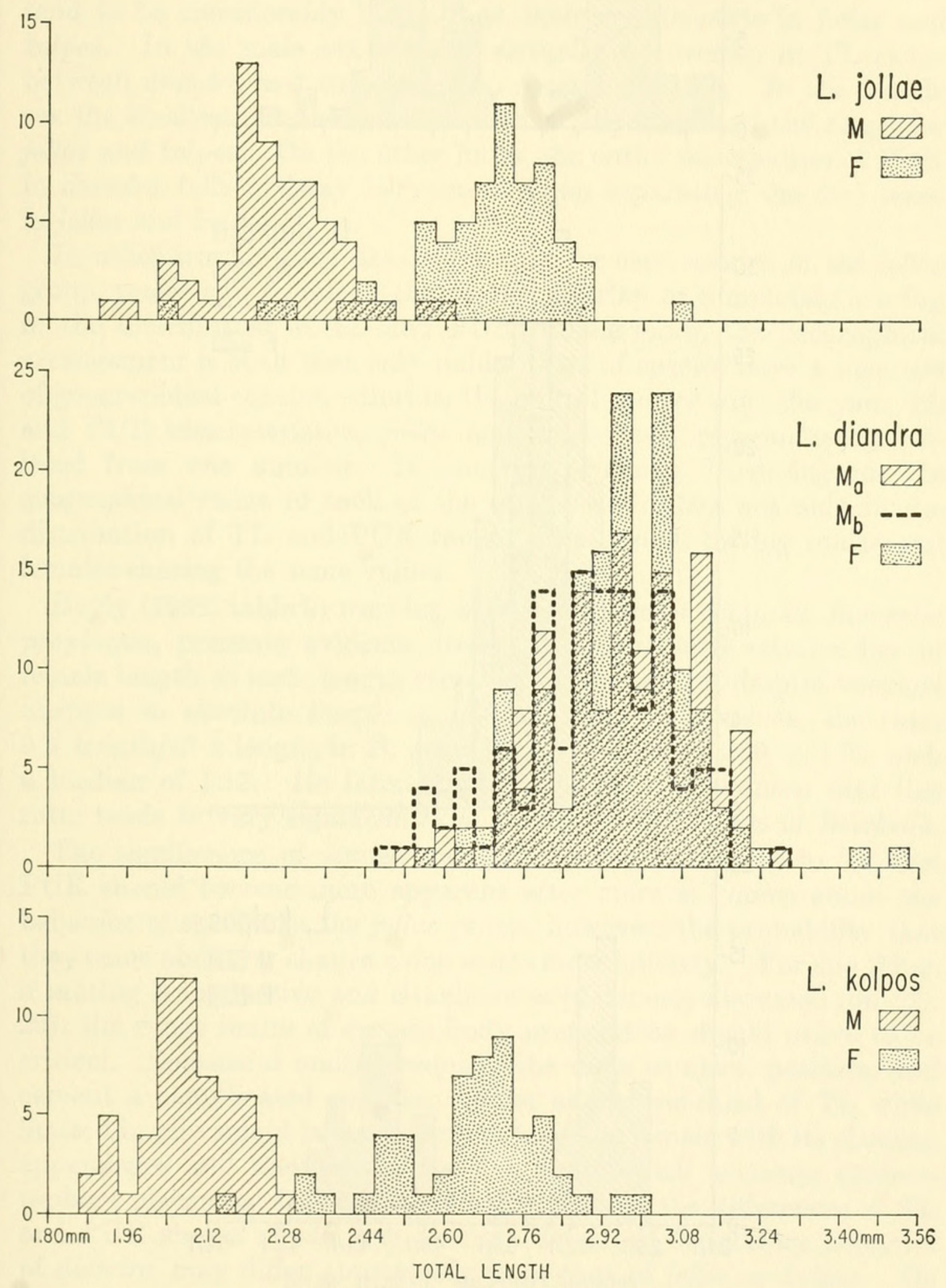

Figure 16.-Distribution of total length in the jollae group. 

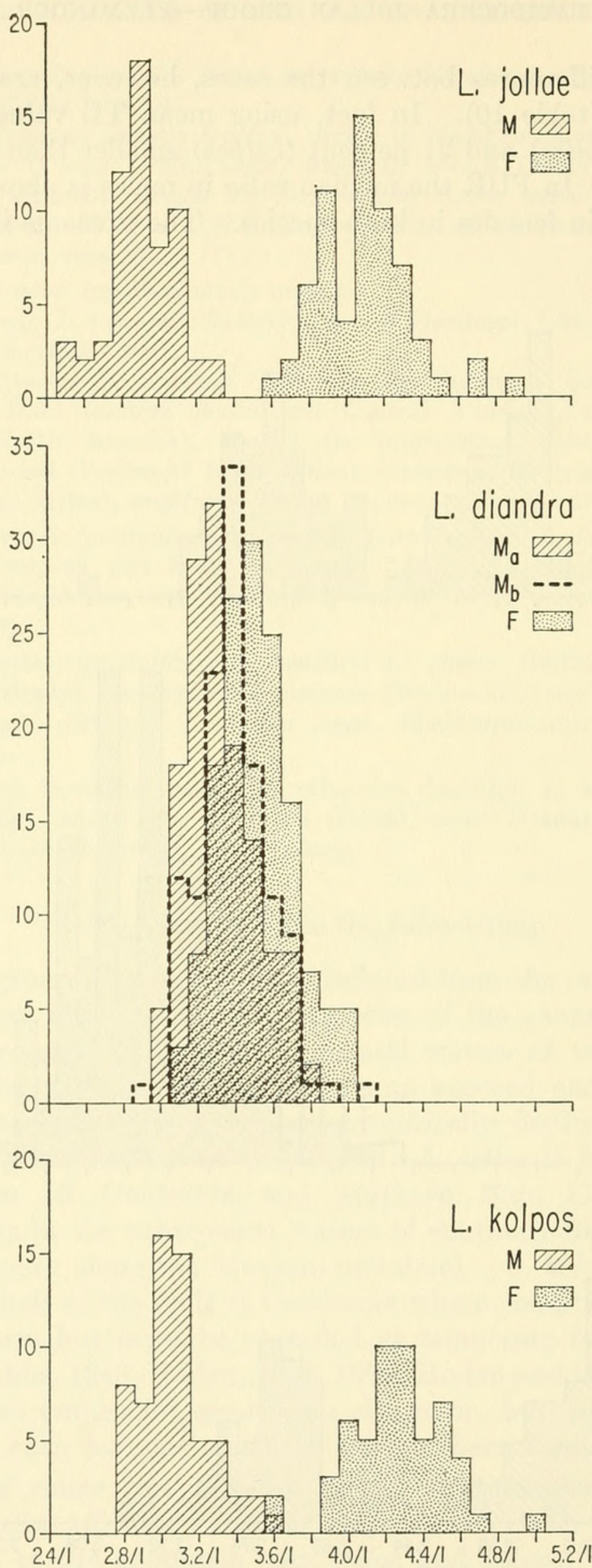

PROSOME - UROSOME LENGTH RATIO

Figure 17.-Distribution of prosome-urosome length ratio in the jollae group. 
slightly larger in males (ca. $0.04 \mathrm{~mm}$ ) despite the larger TL in females. On the other hand, the prosome is about $0.5 \mathrm{~mm}$ smaller in the male.

TL-PUR relationships in diandra are surprisingly different from those in jollae and kolpos. Males and females not only fail to differ appreciably, but have essentially the same ranges, means and medians. There are other notable differences as well. Both sexes of diandra tend to be considerably larger than their counterparts in jollae and kolpos. In the male sex there is virtually no overlap in TL range between diandra and the other two species (fig. 16). In the female sex the smallest sized diandra occur near the middle of the range for jollae and kolpos. On the other hand, the entire distribution of PUR in diandra falls midway between the gap separating the two sexes in jollae and kolpos.

In other words, these data show that for each species of the jollae group, males and females either barely overlap or completely overlap in the distribution of TL and PUR; furthermore, the geographical arrangement is such that only unlike pairs of species have a measure of geographical contact - that is, the pair of species with the same TL and PUR characteristics, jollae and kolpos, are geographically isolated from one another. In contrast, diandra, bordering on the geographical range of each of the other two, differs not only in the distribution of TL and PUR ranges, but also in having males and females sharing the same values.

Bayly (1962, table 9) working with a fresh water calanoid, Boeckella propinqua, presents evidence that the proportional relationship of female length to male length remains fairly constant despite seasonal changes in absolute length of adults. Using his values, the ratio o $\overline{\mathrm{x}}$ length/ $\sigma^{\pi} \overline{\mathrm{x}}$ length in $B$. propinqua varies from 1.09 to 1.24 with a median of 1.12. He later (1964) expressed the opinion that this ratio tends to vary significantly among different species of Boeckella.

The significance of sexual and interspecific differences in TL and PUR should become more apparent after more is known about the behavior of species in the jollae group; however, the probability that they came about by chance alone seems most unlikely. For one thing, if mating is instinctive and ritualistic as previously discussed (pp. 2729 ), the range limits of certain body proportions should prove to be critical. Successful mating requires the male to eject, position, and cement a complicated coupling device about one-third of TL while limited in movement because it must hold the female with its clasping appendages and maintain a position from which accurate spermatophore placement is feasible. On the basis of the differences in TL and PUR shown above, one or more details of copulatory behavior of diandra may differ appreciably from that of jollae or kolpos. On the other hand, there is no reason to anticipate such a difference 
among the morphologically similar but allopatric species, jollae and kolpos.

We can only speculate as to the mechanics of a key-lock mechanism for inhibiting hybrid mating in the jollae group. The existence of such a mechanism at this time rests on the absence of hybrids and the fact that no Labidocera adult female of any species has been seen bearing the spermatophore of another species. In general, copulation in crustaceans occurs soon after the female moults and before the cuticle has hardened. If this is true in pontellids, the possibility of damage makes it unlikely that female secondary sexual characters are subjected to great pressure during clasping or when used as sites for leverage. As noted earlier, the jollae male has been observed holding the female about the urosome with its chela. To avoid injury to the recently moulted female and to permit whatever maneuverability is needed for manipulating and cementing the spermatophore, the chela could serve as a ring loosely encircling the female urosome. The urosome in turn should have the means to prevent both interference with prosome-urosome articulation and separation of the mating pair, i.e., suitably placed anterior and posterior mechanical stops.

In the jollae group the female genital segment anteriorly bears one or more conspicuous swellings and posteriorly it expands gradually in circumference somewhat like a plug. In diandra, a strong shoulder abruptly increases the posterior girth of the elongated genital segment while in jollae and kolpos the right caudal ramus is greatly expanded beyond the lateral limit of the urosome. These otherwise peculiar asymmetries appear to fulfill the requirements for mechanical stops limiting the extent of slippage of an encircling chela. In fact, the arrangement in diandra appears to be equally effective for both male morphs.

\section{Evolution of Specific Characters in the jollae Group}

Comparison of the three species described above reveals one outstanding feature. Despite predominantly allopatric ranges, morphological separation of these species is concentrated in secondary sexual characters. On the other hand, no apparent differences were seen in either feeding or swimming structures unaffected by sexual maturity; that is, the three species show unmistakable evidence of strong selection pressure for diversification of copulatory structures but little to no modification from basic morphology of other adaptive structures.

The possibility that copulatory adaptations differentiated as such in totally allopatric daughter populations cannot be ruled out at this time; however, the likelihood of achieving by chance the orderly 
arrangement of morphology and morphometry seen in the jollae group seems remote indeed.

A more likely alternative is suggested by comparing differences among the geographically contiguous pairs of species with those of the one totally allopatric pair. In contiguous species conspicuous differences appear in both morphology and morphometry. The allopatric pair, jollae and kolpos, are spatially separated by a broad, biogeographically inimical, zone. Morphological distinctions are weak and the two species share the same morphometry.

Turning to the eastern American cognates, Fleminger and Engchow (1966) show that morphological and morphometrical differences among the geographically contiguous species, L. mirabilis and L. wilsoni, closely parallel differences between contiguous pairs of the jollae group (table 11). In wilsoni the two sexes are similar in TL and PUR, in mirabilis they differ conspicuously in both features and to about the same degree as in kolpos and jollae. Some of the more notable morphological differences among the eastern species are the position of the female genital pore, the length of the male's left leg 5 , and the position and extent of development of specialized exopodal spines on male swimming legs.

Table 11 also reveals another surprising feature. Males of the mirabilis group have a median PUR in excess of $5: 1$, while males of the jollae group have a median PUR of less than $3.5: 1$. Could this difference reflect the evolutionary imprint of earlier interactions when sea passages connected the eastern and western American coasts-or did they, too, arise by chance in isolation?

Repetition of the pattern in contiguous species on both coasts and the deviation in the one totally allopatric pair within a group are compelling reasons for exploring further into the argument for interaction. We may assume with Mayr (1963) that incipient reproductive barriers arise in isolated daughter populations as a byproduct of provincial adaptation. In the case of incipient species, the provincialism would impose a selective disadvantage on hybrid mating after geographical isolation breaks down. This in turn would increase selection for strengthening copulation barriers among newly overlapping daughter populations (see reviews of Brown and Wilson, 1956; Blair, 1958; Sibley, 1961; and discussion of Brown, 1957, 1958). Selection for reproductive barriers to reduce hybridization in response to this interaction is usually termed reinforcement. It is akin to character displacement, both being a product of sympatry of closely related species. Reinforcement leads to reproductive incompatability while character displacement permits ecological compatability. 
Natural selection against interactions that waste gametes can be expected to act upon the ethology of mating as well as on the copulatory mechanism. Evidence of ritualization and species-specificity in copepod copulation has already been discussed above. Lacking direct observations, mating ethology, morphology, and morphometry in the jollae and mirabilis groups can be related only by inference. Another necessary assumption is that sympatry of the contiguous species has been more extensive in the past than is indicated by the known distributions. In support of more extensive sympatry is substantial evidence that the California-Mexico coastline has continuously experienced both large and small-scale climatic and hydrographic flux.

The development of the jollae group as a distinct evolutionary unit probably begins with complete emergence of the Panamanian Isthmus and we can safely assume that the group is the outcome of a Quaternary history. Alternating periods of extensive sympatry and allopatry could have followed the familiar pattern of successive warming and cooling trends during North American Pleistocene. Zeuner (1959) points out that biotope replacement occurred about 10 times or more on the continent. Paleontological-geological evidence of the extensive changes that occurred along the Pacific coast has been reviewed by Durham and Allison (1960), Hubbs (1960), and Allison (1964).

Opportunities for variation in range relationships within the jollae group are not necessarily tied to the more or less 10,000-year intervals of glacial and interglacial stages. Within geological epochs we have evidence of more provincial warming and cooling trends that can shift hydrographic and faunal properties hundreds of miles off California and Baja California (Hubbs, 1948; Brinton, 1960; Berner, 1960; Reid, 1960; Berner and Reid, 1961); moreover, on an annual basis seasonal countercurrents flowing from the south alternate with periods of upwelling and concomitant strengthening of California Current flow from the north (Reid, Roden, and Wyllie, 1958; Reid, 1960; Schwartzlose, 1963) provide the pathways for range extensions and intermingling of diandra and jollae. In the Gulf of California monsoonal wind conditions (Roden, 1964) provide diandra and kolpos with similar opportunities. The polymorphism observed in diandra can be regarded as evidence that the species is regularly subjected to extensive environmental changes (Ford, 1964).

Considering their morphological affinities jollae and kolpos were separated recently, perhaps in connection with Wisconsin and postWisconsin events. The cooler phase would have extended the range of the ancestral population south beyond Cabo San Lucas. A northward shift in the range could be expected to follow diminution of the 
cool period. This in effect would trap one segment in the upper Gulf of California while the Pacific coast population retreated north of Magdalena Bay. Parallels have been noted in the temperate fishes of the two regions and accounted for by the same reasoning (Hubbs, 1948; Walker, 1960). Following isolation of the daughter populations, it is likely that the initial adaptations were physiological since the chemical, physical, and climatic properties of the two regions show notable differences. The distinguishing morphological features, centered in sexual structures, could have come about by reinforcement, in response to subsequent genetic exchange between the two populations during especially cold periods.

In the above discussion the action of reinforcement has been proposed as the basis for explaining the extant patterns of morphology with respect to range. Examination of other closely related complexes should be made to obtain more direct evidence that reinforcement occurs in planktonic populations; that is, we should determine whether species-specific differences in an area of overlap between closely related species would be more pronounced than in the allopatric portions of the range of each. Study of Fleminger's (1964) trispinosa group (genus Labidocera) has yielded evidence of reinforcement in several morphological features and will be presented elsewhere in the near future.

Assuming that reinforcement of reproductive isolation is the basis for the extant morphological patterns in the jollae group, why is it that no pair of species has successfully adapted to some degree of sympatry? In the trispinosa group, each pair of adjacent species share several hundred miles of common range but each species' range also includes a more extensive nonoverlapping segment. Another point to consider is whether reinforcement is evidence that the trispinosa group is in an earlier stage of development than that attained by the jollae group. Further study of the biology and distribution of these groups should prove enlightening as to the mechanics of dispersion, gene flow, and competition among planktonic Crustacea.

\section{Summary}

Three closely related species inhabiting coastal waters of western North America and referable to the genus Labidocera are described. Two of the species are new. Geographical relationships among the three species are established and morphological differences compared between allopatric and incompletely sympatric pairs. The location and strength of character differences in the light of geographical relationships is noted and the likelihood that reinforcement of secondary sexual characters has played a major role in evolution within the group is discussed. Mating behavior within the group is also considered. 
A genetic model consistent with varying sex ratios and proportions of polymorphic forms in field collections is proposed to account for the widespread polymorphism discovered in males of one of the new species. The relationship of the jollae group to the remainder of the genus is discussed.

\section{Literature Cited}

Ahlstrom, E. H.

1959. Vertical distribution of pelagic fish eggs and larvae off California and Baja California. Fish. Bull. Fish and Wildlife Serv., vol. 60,

Allison E. C. no. 161 , pp. $107-146$.

1964. Geology of areas bordering the Gulf of California. In Van Andel and Shor, Marine geology of the Gulf of California-A Symposium. American Assoc. Petrol. Geol. Mem., no. 3, pp. 3-29.

Anraku, M.

1954. Gymnoplea Copepoda collected in Aleutian waters in 1953. Bull.

Fac. Fish. Hokkaido Univ., vol. 5, no. 2, pp. 123-136.

Anraku, M., and OMORI, M.

1963. Preliminary survey of the relationship between the feeding habits and the structure of the mouthparts of marine copepods. Limnol. Oceanogr., vol. 8, no. 1, pp. 116-126.

BAYLY, I. A. E.

1962. Ecological studies on New Zealand lacustrine zooplankton with special reference to Boeckella propinqua Sars (Copepoda: Calanoida). Australian Journ. Mar. Freshwater Res., vol. 13, no. 2, pp. 143-197.

1964. A revision of the Australasian species of the freshwater genera Boeckella and Hemiboeckella (Copepoda: Calanoida). Australian Journ. Mar. Freshwater Res., vol. 15, pp. 180-238.

Berlemishev, K. V.

1959. Anatomy of the masticatory apparatus of the copepods, 2: Masticatory edge of the mandibles of certain calanids and eucalanids. Trudy Inst. Okeanol., vol. 30, pp. 148-155. [In Russian.]

Berner, L. D.

1960. Unusual features in the distribution of pelagic tunicates in 1957 and 1958. California Coop. Ocean. Fish. Invest. Rep., vol. 7, pp. 133-135.

Berner, L. D., and Reid, J. L., Jr.

1961. On the response to changing temperature of the temperature-limited plankter Doliolum denticulatum Quoy and Gaimard, 1835. Limnol. Oceanogr., vol. 6, no. 2, pp. 205-215.

BlaIr, W. F.

1958. Distributional patterns of vertebrates in the southern United States in relation to past and present environments. In Hubbs, Zoogeography. American Assoc. Adv. Sci. Symp., no. 51, pp. 433-468.

Bowman, T. E.

1955. A new copepod of the genus Calanus from the northwestern Pacific with notes on Calanus tenuicornis Dana. Pacific Sci., vol. 9, pp. $413-422$.

BRAdY, G. S.

1915. Notes on the pelagic entomostraca of Durban Bay. Ann. Durban Mus., vol. 1, pp. 134-146. 
Brinton, E.

1960. Changes in the distribution of euphausiid crustaceans in the region of the California Current. California Coop. Ocean. Fish. Invest. Rep., vol. 7, pp. 137-146.

1962. The distribution of Pacific euphausiids. Bull. Scripps Inst. Oceanogr., vol. 8, no. 2, pp. 51-270.

Brodsky, K. A.

1950. Calanoida of the polar basin and far eastern seas of the U.S.S.R. Opred. faune SSSR, Akad. Nauk SSSR, vol. 35, 441 pp. [In Russian.]

Brown, W. L., JR.

1957. Centrifugal speciation. Quart. Rev. Biol., vol. 32, no. 3, pp. 247-277.

1958. Some zoological concepts applied to problems in evolution of the hominid lineage. American Sci., vol. 46, no. 2, pp. 151-158.

Brown, W. L., Jr., and Wilson, E. O.

1956. Character displacement. Syst. Zool., vol. 5, pp. 49-64.

Cameron, F. E.

1957. Some factors influencing the distribution of pelagic copepods in the Queen Charlotte Islands. Journ. Fish Res. Bd. Canada, vol. 14, no. 2, pp. 165-202.

Campbell, M. H.

1929a. A preliminary quantitative survey of the zooplankton in the Straits of Georgia. Trans. Roy. Soc. Canada, vol. 23, 28 pp.

1929b. Some free-swimming copepods of the Vancouver Island region. Trans. Roy. Soc. Canada, vol. 23, pp. 303-332.

1930. Some free-swimming copepods of the Vancouver Island region, 2 . Trans. Roy. Soc. Canada, vol. 24, pp. 177-182.

Cohen, M. J., and DiJkgraaf, S.

1961. Mechanoreception. In Waterman, The physiology of Crustacea, vol. 2, pp. 65-108.

Dakin, W. J., and Colefax, A. N.

1940. The plankton of the Australian coastal waters of New South Wales,

Davies, J. L.

1. Univ. Sydney Publ. Dept. Zool. Monogr., no. 1, 215 pp.

1963. The antitropical factor in cetacean speciation. Evolution, vol. 17, pp. 107-116.

Davis, C. C.

1949. The pelagic Copepoda of the northeastern Pacific Ocean. Univ.

Washington Publ. Biol., vol. 14, 118 pp.

Durham, J. W., and Allison, E. C.

1960. The geologic history of Baja California and its marine faunas. Syst. Zool., vol. 9, no. 2, pp. 47-91.

Ebeling, A. W.

1962. Melamphaidae, 1: Systematics and zoogeography of the species in the bathypelagic fish genus Melamphaes Günther. Dana Rep., no. 58, 164 pp.

Ekman, S.

1953. Zoogeography of the sea, $417 \mathrm{pp}$.

Esterly, C. O.

1905. The pelagic Copepoda of the San Diego region. Univ. California Publ. Zool., vol. 2, no. 4, pp. 113-233.

1906. Additions to the copepod fauna of the San Diego region. Univ. California Publ. Zool., vol. 3, no. 5, pp. 53-92. 
1924. Free-swimming Copepoda of San Francisco Bay. Univ. California Publ. Zool., vol. 26, no. 5, pp. 81-129.

Fahrenbach, W. H.

1962. The biology of a harpacticoid copepod. La Cellule, vol. 62, no. 3, pp. 302-376.

Farran, G. P.

1936. Copepoda. In vol. 5 of Scientific Reports of the Great Barrier Reef Expedition, 1928-29, pp. 73-142.

Fleminger, A.

[1956.] Taxonomic and distributional studies on the epiplanktonic calanoid copepods (Crustacea) of the Gulf of Mexico. Harvard Univ., Dept. Biology, unpublished Ph. D. dissertation, 317 pp.

1957. New calanoid copepods of Pontella Dana and Labidocera Lubbock with notes on the distribution of the genera in the Gulf of Mexico. Tulane Stud. Zool., vol. 5, no. 2, pp. 19-34.

1959. Distribution of calanoid copepods in the Gulf of Mexico. Internat. Oceanogr. Congr., pp. 154-155. [Preprints.]

1964a. Labidocera johnsoni, species nov. Crustacea: Copepoda: Calanoida: Pontellidae. Pilot Register Zool., card nos. 3-A,B.

1964b. Distributional atlas of calanoid copepods in the California Current region, 1. California Coop. Oceanogr. Fish. Invest., atlas, no. 2, $\mathrm{xvi}+313 \mathrm{pp}$.

1965. On some Pacific species of Labidocera and Stephos reported by C. B. Wilson (1950). Crustaceana, vol. 8, no. 2, pp. 121-130.

Fleminger, A., and Tan, Engchow

1966. The Labidocera mirabilis species group (Copepoda: Calanoida) with description of a new Bahamian species. Crustaceana, vol.

Ford, E. B. 11, pt. 3, pp. 291-301, figs. 1-4.

1964. Ecological genetics, $335 \mathrm{pp}$.

GAULD, D. T.

1957. Copulation in calanoid copepods. Nature, vol. 180, p. 510.

Gehringer, J. W.

1952. An all-metal plankton sampler (model Gulf III). Fish and Wildlife Serv. Spec. Sci. Rep. Fish., no. 88, pp. 7-12.

Giesbrecht, W.

1892. Systematik und Faunistik der Pelagischen Copepoden des Golfes von

Neapel. Fauna und Flora des Golfes von Neapel, vol. 19, 831 pp.

1895. Die pelagischen Copepoden. Bull. Mus. Comp. Zool., vol. 25, no. 12, pp. 243-263.

Giesbrecht, W., and Schmeil, O.

1898. Copepoda, 1: Gymoplea. Das Tierreich, vol. 6, 169 pp.

Gooding, R. U.

1957. On some Copepoda from Plymouth, mainly associated with invertebrates, including three new species. Journ. Mar. Biol. Assoc. United Kingdom, vol. 36, pp. 195-221.

1960. North and South American copepods of the genus Hemicyclops (Cyclopoida: Clausidiidae). Proc. U.S. Nat. Mus., vol. 112, no. 3434, pp. 159-195.

$\mathrm{H}_{\mathrm{AQ}}$, S. M.

1960. Dimorphic males and some aspects of the biology of Euterpina acutifrons Dana. Rep. Challenger Soc., vol. 3, no. 12 (abstract). 
1965. Development of the copepod Euterpina acutifrons with special reference to dimorphism in the male. Proc. Zool. Soc. London, vol.

Heberer, G. 144, pt. 2, pp. $175-201$.

1932. Untersuchungen über Bau und Funktion der Genital-organe der Copepoden, 1: Der männliche Genetalapparat der calanoiden Copepoden. Zeitschr. Mikr.-Anat. Forsch., vol. 31, pp. 250-424.

Heinrich, A. K.

1960. On the surface plankton of the central part of the Pacific Ocean. Trudy Inst. Okeanol., vol. 41, pp. 42-47. [In Russian.]

Hill, L. L., and Coker, R. E.

1930. Observations on mating habits of Cyclops. Journ. Elisha Mitchell

HuBBs, C. L. Sci. Soc., vol. 45 , no. 2, pp. 206-220.

1948. Changes in the fish fauna of western North America correlated with changes in ocean temperatures. Journ. Mar. Res., vol. 7, pp. 459482.

1960. The marine vertebrates of the outer coast. Syst. Zool., vol. 9, nos. 3-4, pp. 134-147.

ILLG, P. L.

1958. North American copepods of the family Notodelphyidae. Proc. U.S. Nat. Mus., vol. 107, no. 3390, pp. 463-649.

JACOBS, J.

1961. Laboratory cultivation of the marine copepod Pseudodiaptomus JoHnson, M. W. coronatus Williams. Limnol. Oceanogr., vol. 6, no. 4, pp. 443-446.

1932. Seasonal distribution of plankton at Friday Harbor, Washington. Univ. Washington Publ. Oceanogr., vol. 1, no. 1, 38 pp.

1935. The developmental stages of Labidocera. Biol. Bull., vol. 68, no. 3, pp. 397-421.

1948. The postembryonic development of the copepod Pseudodiaptomus euryhalinus Johnson and its phylogenetic significance. Trans. American Microse. Soc., vol. 67, no. 4, pp. 319-330.

1964. On a new species of Pseudodiaptomus from the west coast of Mexico, Costa Rica and Ecuador (Copepoda). Crustaceana, vol. 7, pp. 33-41.

Le Brasseur, R. J.

1955. Oceanography of British Columbia mainland inlets, 6: Plankton distribution. Fish. Res. Bd. Canada, Pacific Prog. Rep., no. 103, pp. 19-21.

1956a. Zooplankton distribution in the northeast Pacific Ocean. Fish. Res. Bd. Canada, Pacific Prog. Rep., no. 107, pp. 3-5.

1956b. Distribution of zooplankton in Dixon Entrance. Fish. Res. Bd. Canada, Pacific Prog. Rep., no. 107, pp. 5-7.

LEGARE, J. E. H.

1957. The qualitative and quantitative distribution of plankton in the Strait of Georgia in relation to certain oceanographic factors. Journ. Fish. Res. Bd. Canada, vol. 14, no. 4, pp. 521-552.

LUввоск, J.

1853. Description of a new genus of Calanidae. Ann. Mag. Nat. Hist., ser. 2 , vol. 11 , pp. 25-29.

$221-531-67-4$ 
MAYR, E.

1963. Animal species and evolution, $797 \mathrm{pp}$.

Parker, G. H.

1902. The reaction of copepods to various stimuli and the bearing of this on daily depth migrations. U.S. Fish. Comm. Bull. 1901, pp. 103123.

REID, J. L., JR.

1960. Oceanography of the eastern North Pacific in the last ten years. California Coop. Ocean. Fish. Rep., vol. 7, pp. 77-90.

Reid, J. L., JR.; Roden, G. I.; and Wrllie, J. G.

1958. Studies of the California Current system. California Coop. Ocean. Fish. Invest. Prog. Rep., 1 July 1956-1 January 1958, pp. 27-56.

Roden, G. I.

1958. Oceanographic and meteorological aspects of the Gulf of California. Pacific Sci., vol. 12, pp. 21-45.

1964. Oceanographic aspects of Gulf of California. In Marine geology of the Gulf of California-A symposium. American Assoc. Petrol. Geol. Mem., no. 3, pp. 30-58.

Roden, G. I., and Groves, G. W.

1959. Recent oceanographic investigations in the Gulf of California. Journ. Mar. Res., vol. 18, no. 1, pp. 10-35.

Rose, M.

1933. Copépodes pélagiques. Faune de France, no. 26, 374 pp.

Schoener, T. W.

1965. The evolution of bill size differences among sympatric congeneric species of birds. Evolution, vol. 19, no. 2, pp. 189-213.

Schwartzlose, R. A.

1963. Nearshore currents of the western United States and Baja California as measured by drift bottles. California Coop. Ocean. Fish Invest. Rep., vol. 9, pp. 15-21.

Sewell, R. B. S.

1956. The continental drift theory and the distribution of the Copepoda. Proc. Linn. Soc. London, Session 166, 1953-54, pts. 1-2, pp. 149-177.

Sherman, K.

1963. Pontellid copepod distribution in relation to surface water types in the central North Pacific. Limnol. Oceanogr., vol. 8, no. 2, pp. 214-227.

1964. Pontellid copepod occurrence in the central South Pacific. Limnol. Oceanogr., vol. 9, no. 4, pp. 476-484.

Sibley, C. G.

1961. Hybridization and isolating mechanisms. In Blair, Vertebrate speciation, pp. 69-88.

Simpson, G. G.

1961. Principles of animal taxonomy, $247 \mathrm{pp}$.

Voronina, N. M.

1962. On the surface plankton of the Indian Ocean. Trudy Inst. Okeanol., vol. 58, pp. 67-79. [In Russian.]

1964. The distribution of surface plankton in the Pacific Equatorial Current area. Trudy Inst. Okeanol., vol. 65, pp. 95-106. [In Russian.]

WALKer, B. W.

1960. The distribution and affinities of the marine fish fauna of the Gulf of

California. Syst. Zool., vol. 9, nos. 3-4, pp. 123-133. 
WheEler, W. M.

1900. The free-swimming copepods of the Woods Hole region. U.S. Fish. Comm. Bull. 1899, pp. 157-192.

Wilson, C. B.

1932. The copepod crustaceans of Chesapeake Bay. Proc. U.S. Nat. Mus., vol. 80, no. 2915, art. 15, 54 pp.

1942. The copopods of the plankton gathered during the last cruise of the Carnegie. No. 1 of Biology in Scientific results of Cruise 7 of the Carnegie during 1928-1929 . . . (Carnegie Institute of Washington Publication 536), v +237 pp.

1950. Copepods gathered by the United States Fisheries Steamer Albatross from 1887 to 1909, chiefly in the Pacific Ocean. U.S. Nat. Mus. Bull. 100, vol. 14, pt. 4, pp. i-ix+141-441.

ZEUNER, F. E.

1959. The Pleistocene Period: Its climate, chronology, and faunal successions, $447 \mathrm{pp}$. 


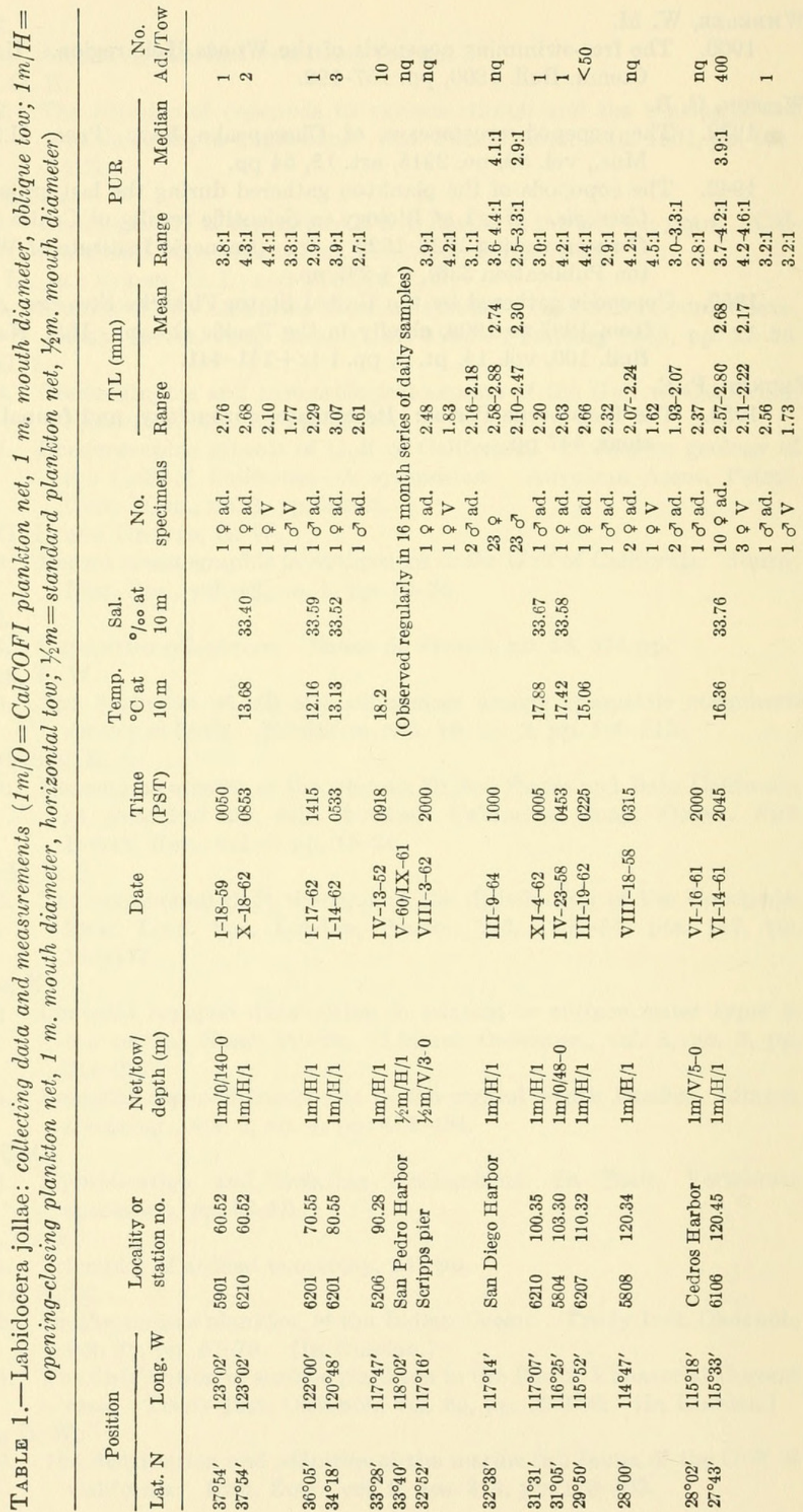




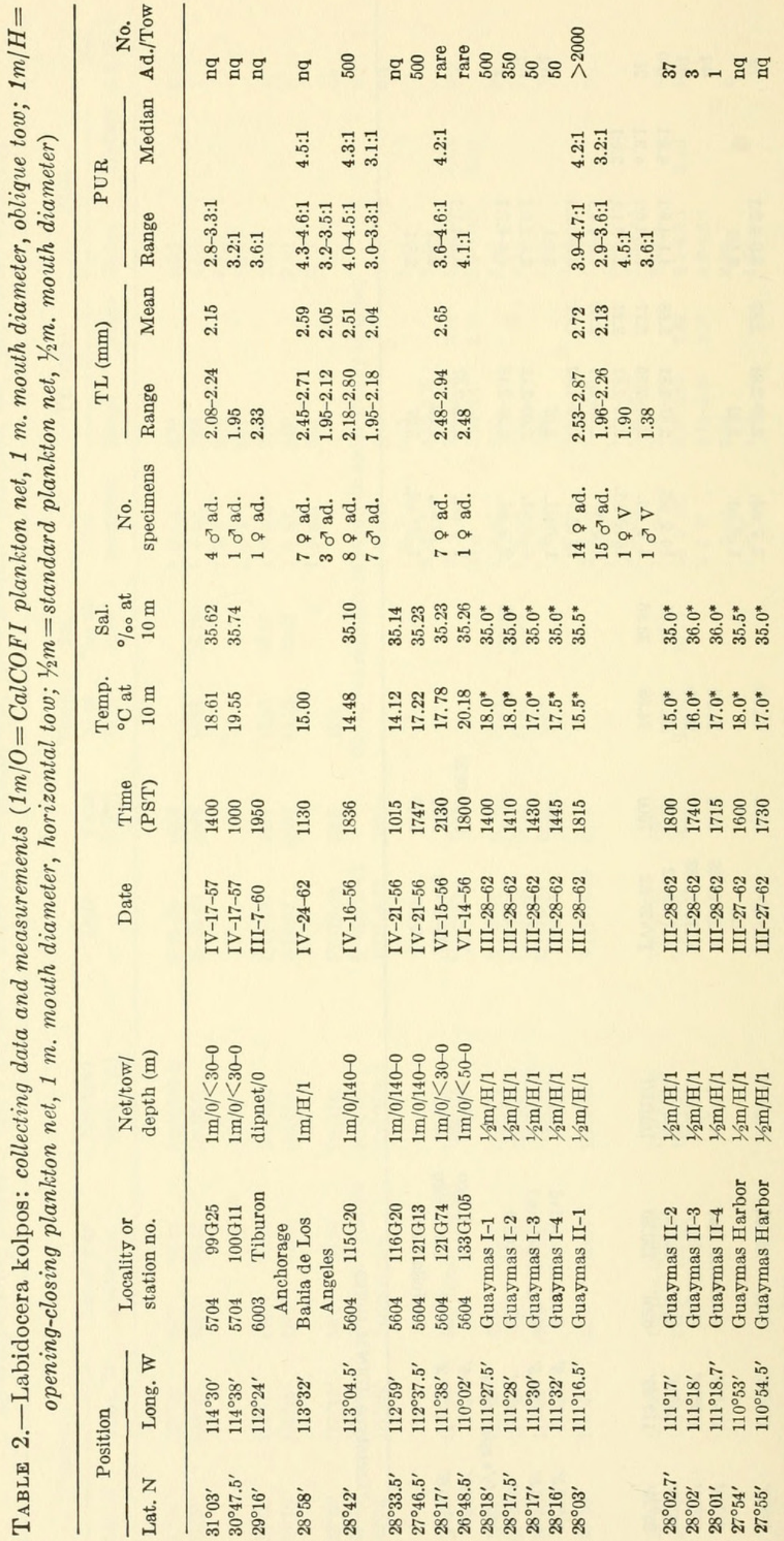




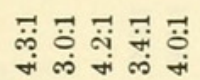

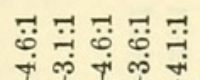

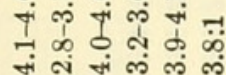

돗ำ

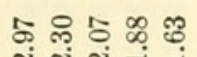

ง จ

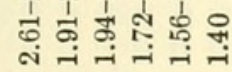

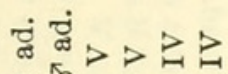

o $\begin{array}{lll}0 \\ 0\end{array}$

훌

is : *0

ผึं

*0.

웅:

จุ สำ

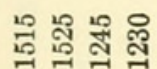

곡뮴영

뭉 뭉 뚜 융

고영 क् क

当当当

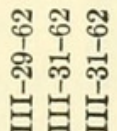

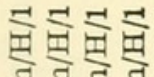

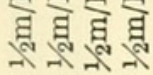

ปี่ง

日记云

速 : :

수 훙옹

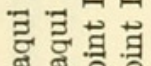

त्र

is is is is

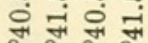

을

is is

फ़ं क्षें

ฝู่ลำ ลิ

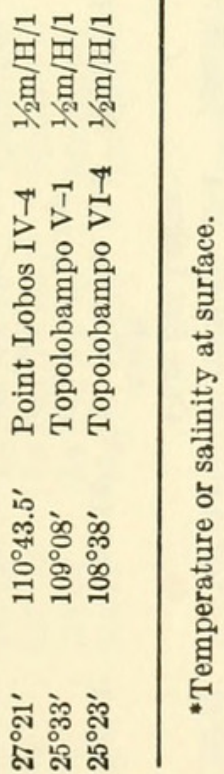




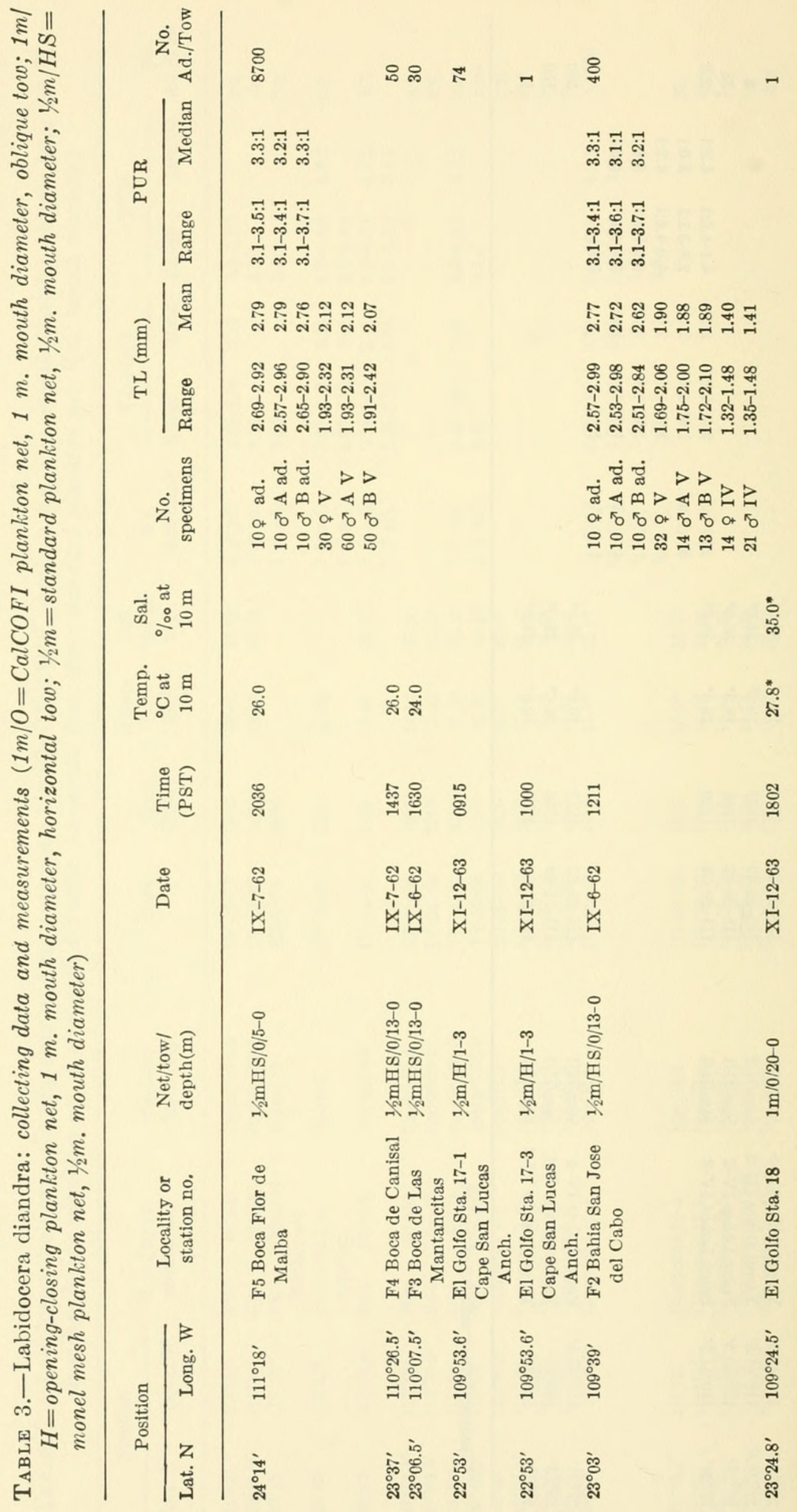




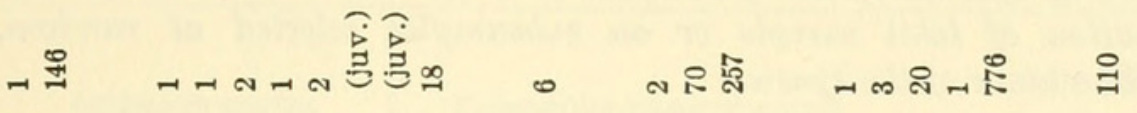

\begin{tabular}{|c|c|}
\hline 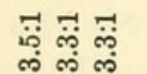 & 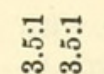 \\
\hline
\end{tabular}

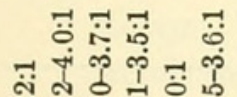

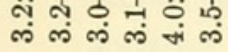

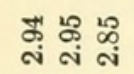

5웅

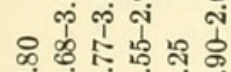
๙

. में वं

लं क्षँ $₫ \wedge>$

ot ${ }^{\circ} 5^{5} \mathrm{~S}^{\circ}$ ot of

一品范踏

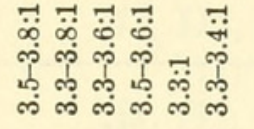

풍

क

ले

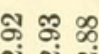

으무 푸

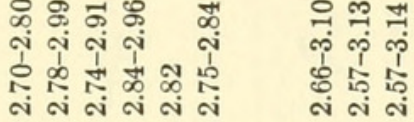

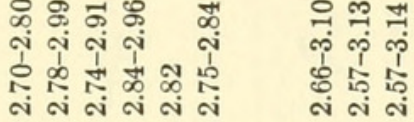

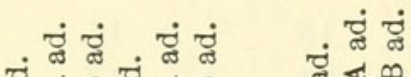

官

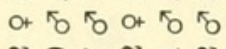

ก 1 N N

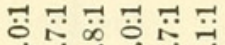
† ๆิ

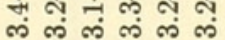

$8=8 \%$ 웅

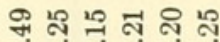
๓

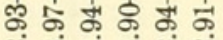
ง ส่ ส่ ก่

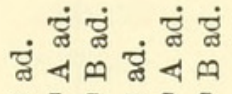

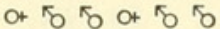
กิสิ ลิ สิ

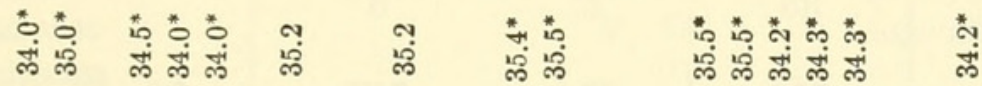

*ำ

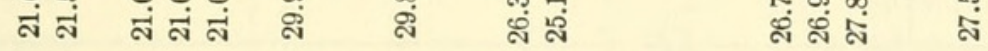

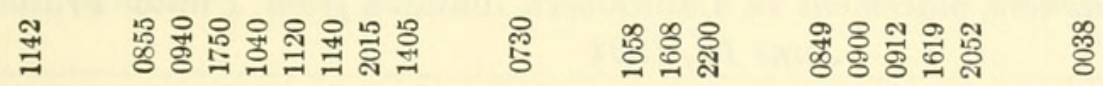

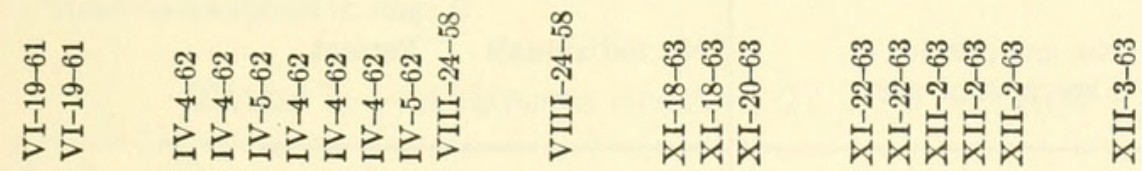

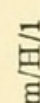

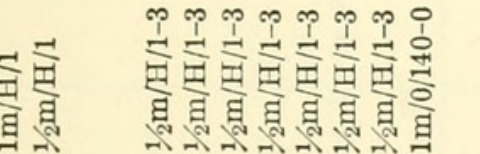

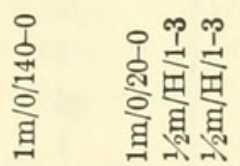

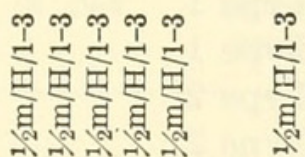

疍

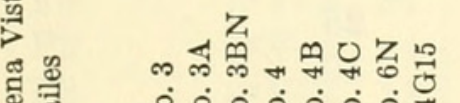

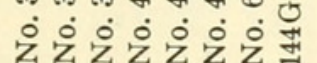

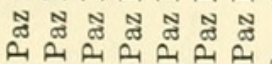

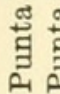

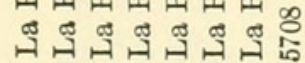

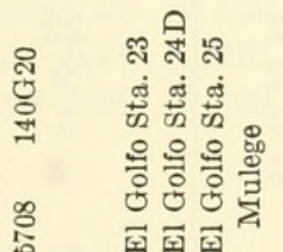

承 옹

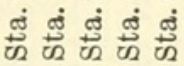
is ㅇㅎㅎㅇㅇㅎㅇ

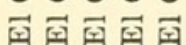

\section{is. \\ 엉}

is in is is is i

今.

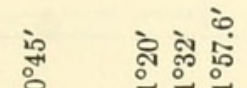

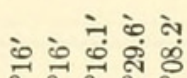

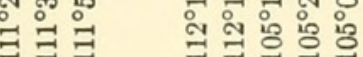

\section{कृ} ๙ัฒ

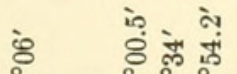
㲾

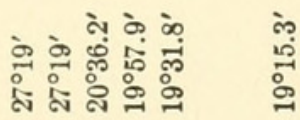


TABLE 4.-Frequency of spermatophore placement in Labidocera diandra (counts based on examination of total sample or on subsamples selected at random, depending upon abundance of the species)

\begin{tabular}{l|ccccc}
\hline \multicolumn{1}{c|}{ Station } & $\begin{array}{c}\text { No. adult } \\
\text { females } \\
\text { observed }\end{array}$ & $\begin{array}{c}\text { No. with } \\
\text { spermat- } \\
\text { ophore }\end{array}$ & $\begin{array}{c}\text { No. with } \\
\text { type 1 } \\
\text { placement }\end{array}$ & $\begin{array}{c}\text { No. with } \\
\text { type 1 } \\
\text { and 2 } \\
\text { placements }\end{array}$ & $\begin{array}{c}\text { No. with } \\
\text { type 2 } \\
\text { placement }\end{array}$ \\
\hline Punta Frailes & 86 & 65 & 25 & 34 & 6 \\
F2 & 3 & 2 & 2 & & \\
F3 & 3 & 1 & 1 & & \\
F4 & 1 & 1 & 1 & & \\
F5 & 124 & 19 & 18 & & 1 \\
5708 140G20 & 2 & 1 & 1 & & \\
5708 144G15 & 2 & 18 & 11 & 6 & 1 \\
El Golfo 17-1 & 22 & 61 & 47 & 12 & 2 \\
El Golfo 24D & 66 & 29 & 29 & & \\
El Golfo 25 & 54 & 72 & 67 & 4 & 1 \\
El Golfo 41 & 353 & 5 & 5 & & \\
El Golfo 42 & 38 & 274 & 207 & 56 & 1 \\
$\quad$ Totals (12) & 754 & 36 & 76 & 20 & 4 \\
$\quad$ Percent & & & & & \\
\hline
\end{tabular}

TABLE 5.-Spermatophore placement in Labidocera diandra from Punta Frailes, June 19, 1961

\begin{tabular}{l|cc}
\hline $\begin{array}{c}\text { No. and position of } \\
\text { spermatophores }\end{array}$ & No. individuals & Percent \\
\hline & 21 & 24 \\
1-Type 1 & 25 & 28 \\
2-Type 1 & 2 & 2 \\
3-Type 1 & 1 & 1 \\
1-Type 2 & 4 & 5 \\
2-Type 2 & 1 & 1 \\
4-Type 2 & 1 & 1 \\
1-Type 1, 1-Type 2 & 22 & 25 \\
1-Type 1, 2-Type 2 & 9 & 10 \\
1-Type 1, 3-Type 2 & 1 & 1 \\
2-Type 1, 1-Type 2 & 2 & 2 \\
Totals & 89 & 100 \\
& & \\
\hline
\end{tabular}


TABLE 6.-Presence of head-hooks

\begin{tabular}{|c|c|c|c|}
\hline \multirow{2}{*}{ Labidocera species } & \multirow{2}{*}{ Copepodite stages observed } & \multicolumn{2}{|c|}{ Head-hooks } \\
\hline & & Immature stages & Adults \\
\hline acuta & II II IV V VI & absent & absont \\
\hline acutifrons & III, IV, V, VI & absent & absent \\
\hline aestiva & II, III, IV, V, VI & absent & absent \\
\hline bataviae & V, VI & absent & absent \\
\hline fluviatilus & IV, V, VI & absent & absent \\
\hline detruncata & IV, V, VI & absent & absent \\
\hline lubbockii & II, III, IV, V, VI & absent & absent \\
\hline mirabilis & II, III, IV, V, VI & absent & absent \\
\hline nerii & III, IV, V, VI & absent & absent \\
\hline johnsoni & III, IV, V, VI & absent & absent \\
\hline wilsoni & III, IV, V, VI & absent & absent \\
\hline scotti & III, IV, V, VI & absent & absent \\
\hline trispinosa & I, II, III, IV, V, VI & absent & absent \\
\hline diandra & I, II, III, IV, V, VI & present* & absent \\
\hline madurae & $\mathrm{V}, \mathrm{VI}$ & absent & absent \\
\hline pectinata & VI & & present \\
\hline jollae & I, II, III, IV, V, VI & present* & present \\
\hline kolpos & IV, V, VI & present & present \\
\hline kröyeri & IV, V, VI & present & usually \\
\hline minuta & IV, V, VI & present & present \\
\hline
\end{tabular}

*Head-hooks absent in stage 1.

TABLE 7.-Labidocera diandra, $T L: P 5, \sigma^{7}$ stage $V, A$ and $B$

\begin{tabular}{|c|c|c|c|c|c|c|c|c|}
\hline \multirow{2}{*}{ Sample } & \multirow{2}{*}{ Class } & \multirow{2}{*}{ No. } & \multicolumn{3}{|c|}{ P5 } & \multicolumn{3}{|c|}{ TL } \\
\hline & & & $\begin{array}{c}\text { Range } \\
(\mathrm{mm})\end{array}$ & $\begin{array}{l}\text { Mean } \\
(\mathrm{mm})\end{array}$ & St. Dev. & $\begin{array}{l}\text { Range } \\
(\mathrm{mm})\end{array}$ & $\begin{array}{l}\text { Mean } \\
(\mathrm{mm})\end{array}$ & St. Dev. \\
\hline F5 & $\sigma^{2} V-1$ & 59 & $0.59-0.68$ & 0.658 & .0217 & $1.91-2.32$ & 2.12 & .083 \\
\hline F5 & $\sigma^{7} \mathrm{~V}-2$ & 51 & $0.47-0.55$ & 0.529 & .0065 & $1.90-2.24$ & 2.07 & .063 \\
\hline $\mathrm{F} 2$ & $\sigma^{2} V-1$ & 14 & $0.58-0.66$ & 0.621 & .0244 & $1.72-2.01$ & 1.885 & .074 \\
\hline F2 & $\sigma^{7} \mathrm{~V}-2$ & 13 & $0.43-0.55$ & 0.504 & 0324 & $1.72-2.10$ & 1.889 & .123 \\
\hline \multicolumn{9}{|c|}{ Pooled data: } \\
\hline & ఠ্ VI-A & 74 & & & & $2.56-3.11$ & 2.91 & .1017 \\
\hline & $\sigma^{7} \mathrm{VI}-\mathrm{B}$ & 52 & & & & $2.52-2.99$ & 2.83 & .1009 \\
\hline
\end{tabular}




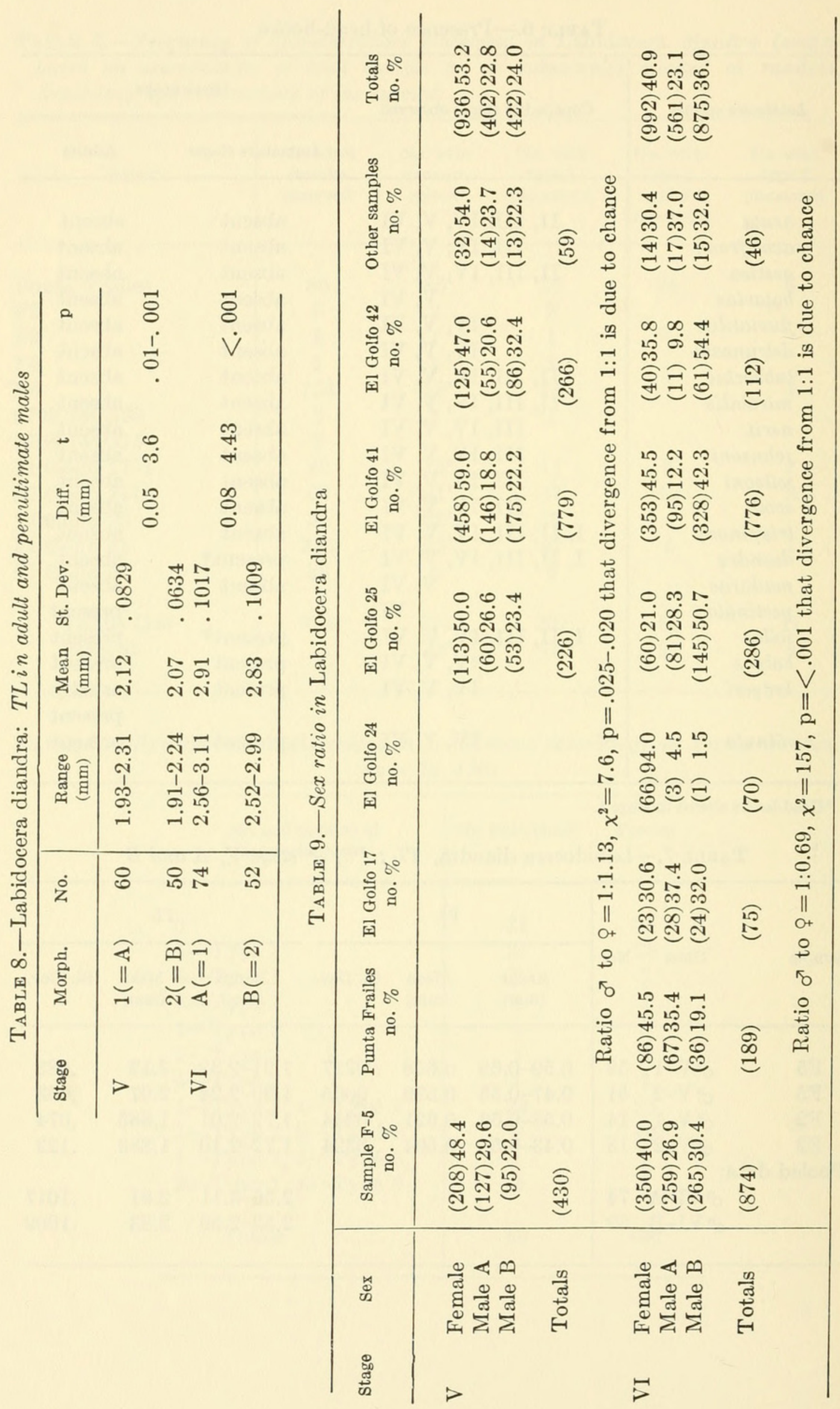


TABLE 10.-TL-PUR in jollae group

\begin{tabular}{|c|c|c|c|c|c|c|c|}
\hline \multirow{2}{*}{$\begin{array}{l}\text { Labidocera } \\
\text { species }\end{array}$} & \multirow{2}{*}{ Sex } & \multirow{2}{*}{ No. } & \multicolumn{3}{|c|}{ TL } & \multicolumn{2}{|c|}{ PUR } \\
\hline & & & $\begin{array}{l}\text { Range } \\
(\mathrm{mm})\end{array}$ & $\begin{array}{l}\text { Mean } \\
(\mathrm{mm})\end{array}$ & St. Dev. & Range & Median \\
\hline \multirow[t]{2}{*}{ jollae } & q & 63 & $2.07-3.07$ & 2.69 & .152 & $3.6-4.9: 1$ & 4.1:1 \\
\hline & $\sigma^{7}$ & 60 & $1.93-2.61$ & 2.26 & .121 & $2.5-3.3: 1$ & $2.9: 1$ \\
\hline \multirow[t]{2}{*}{ kolpos } & q & 54 & $2.18-2.97$ & 2.66 & .152 & $3.6-5.0: 1$ & 4.3:1 \\
\hline & $\sigma^{7}$ & 61 & $1.91-2.30$ & 2.10 & .089 & $2.8-3.6: 1$ & $3.0: 1$ \\
\hline \multirow[t]{3}{*}{ diandra } & q & 144 & $2.57-3.49$ & 2.95 & .140 & $3.1-4.0: 1$ & $3.5: 1$ \\
\hline & $\sigma^{7} \mathrm{~A}$ & 135 & $2.53-3.25$ & 2.95 & .148 & $3.0-3.8: 1$ & $3.3: 1$ \\
\hline & $\sigma^{7} \mathrm{~B}$ & 122 & $2.51-3.25$ & 2.89 & .152 & $2.9-4.1: 1$ & $3.4: 1$ \\
\hline
\end{tabular}

$\mathrm{T}_{\mathrm{ABLE}}$ 11.-Sexual differences in $T L$ and $P U R$ in the wilsoni superspecies

\begin{tabular}{|c|c|c|c|c|c|c|}
\hline \multirow{2}{*}{$\begin{array}{l}\text { Labidocera } \\
\text { species }\end{array}$} & \multicolumn{3}{|c|}{ TL, Mean (mm) } & \multicolumn{3}{|c|}{ PUR, median } \\
\hline & $\sigma^{7}$ & \& & ণ: $\sigma^{7}$ ratio & $\sigma^{x}$ & \& & $\sigma^{\top}:$ : difference \\
\hline \multicolumn{7}{|l|}{ Eastern species* } \\
\hline wilsoni & 2.41 & 2.54 & $1.05: 1$ & $5.2: 1$ & $5.2: 1$ & 0 \\
\hline mirabilis & 2.37 & 2.80 & $1.18: 1$ & $5.1: 1$ & $3.8: 1$ & $1.3: 1$ \\
\hline \multicolumn{7}{|l|}{ Western species } \\
\hline jollae & 2.26 & 2.69 & $1.19: 1$ & $2.9: 1$ & 4.1:1 & 1.2:1 \\
\hline \multirow[t]{2}{*}{ diandra } & 2.95 & 2.95 & $1.00: 1$ & $3.3: 1$ & $3.5: 1$ & $0.2: 1$ \\
\hline & 2.89 & & 1.02:1 & $3.4: 1$ & & $0.1: 1$ \\
\hline kolpos & 2.10 & 2.66 & $1.27: 1$ & $3.0: 1$ & $4.3: 1$ & $1.3: 1$ \\
\hline
\end{tabular}

*Data from Fleminger and Tan (1966). 


\section{$2 \mathrm{BHL}$ Biodiversity Heritage Library}

Fleminger, Abraham. 1967. "Taxonomy, distribution, and polymorphism in the Labidocera jollae group with remarks on evolution within the group (Copepoda: Calanoida)." Proceedings of the United States National Museum 120(3567), 1-61. https://doi.org/10.5479/si.00963801.120-3567.1.

View This Item Online: https://www.biodiversitylibrary.org/item/53446

DOI: https://doi.org/10.5479/si.00963801.120-3567.1

Permalink: https://www.biodiversitylibrary.org/partpdf/52077

\section{Holding Institution}

Smithsonian Libraries

\section{Sponsored by}

Smithsonian

\section{Copyright \& Reuse}

Copyright Status: Public domain. The BHL considers that this work is no longer under copyright protection.

This document was created from content at the Biodiversity Heritage Library, the world's largest open access digital library for biodiversity literature and archives. Visit BHL at https://www.biodiversitylibrary.org. 